\title{
Depolarization ratios retrieved by AERONET sun-sky radiometer data and comparison to depolarization ratios measured with lidar
}

\author{
Youngmin Noh ${ }^{1}$, Detlef Müller ${ }^{2}$, Kyunghwa Lee ${ }^{3}$, Kwanchul Kim $^{3}$, Kwonho Lee ${ }^{4}$, Atsushi Shimizu ${ }^{5}$, Itaru Sano ${ }^{6}$, and \\ Chan Bong Park ${ }^{7}$ \\ ${ }^{1}$ International Environmental Research Center, Gwangju Institute of Science and Technology (GIST), Gwangju, South Korea \\ ${ }^{2}$ School of Physics, Astronomy and Mathematics, University of Hertfordshire, Hertfordshire, UK \\ ${ }^{3}$ Gwangju Institute of Science and Technology (GIST), Gwangju, South Korea \\ ${ }^{4}$ Department of Atmospheric and Environmental Sciences, Gangneung-Wonju National University, Gangneung, South Korea \\ ${ }^{5}$ National Institute for Environmental Studies, Tsukuba, Japan \\ ${ }^{6}$ Graduate School of Science and Engineering, Kindai University, Osaka, Japan \\ ${ }^{7}$ Department of Electronic Engineering, Mokwon University, Daejeon, South Korea
}

Correspondence to: Detlef Müller (d.mueller@herts.ac.uk)

Received: 29 December 2016 - Discussion started: 17 February 2017

Revised: 18 April 2017 - Accepted: 26 April 2017 - Published: 22 May 2017

\begin{abstract}
The linear particle depolarization ratios at 440, 675,870 , and $1020 \mathrm{~nm}$ were derived using data taken with the AERONET sun-sky radiometer at Seoul $\left(37.45^{\circ} \mathrm{N}\right.$, $\left.126.95^{\circ} \mathrm{E}\right)$, Kongju $\left(36.47^{\circ} \mathrm{N}, 127.14^{\circ} \mathrm{E}\right)$, Gosan $\left(33.29^{\circ} \mathrm{N}\right.$, $\left.126.16^{\circ} \mathrm{E}\right)$, and Osaka $\left(34.65^{\circ} \mathrm{N}, 135.59^{\circ} \mathrm{E}\right)$. The results are compared to the linear particle depolarization ratio measured by lidar at $532 \mathrm{~nm}$. The correlation coefficient $R^{2}$ between the linear particle depolarization ratio derived by AERONET data at $1020 \mathrm{~nm}$ and the linear particle depolarization ratio measured with lidar at $532 \mathrm{~nm}$ is $0.90,0.92,0.79$, and 0.89 at Seoul, Kongju, Gosan, and Osaka, respectively. The correlation coefficients between the lidar-measured depolarization ratio at $532 \mathrm{~nm}$ and that retrieved by AERONET at $870 \mathrm{~nm}$ are 0.89, 0.92, 0.76, and 0.88 at Seoul, Kongju, Gosan, and Osaka, respectively. The correlation coefficients for the data taken at $675 \mathrm{~nm}$ are lower than the correlation coefficients at 870 and $1020 \mathrm{~nm}$, respectively. Values are $0.81,0.90,0.64$, and 0.81 at Seoul, Kongju, Gosan, and Osaka, respectively. The lowest correlation values are found for the AERONET-derived linear particle depolarization ratio at $440 \mathrm{~nm}$, i.e., $0.38,0.62,0.26$, and 0.28 at Seoul, Kongju, Gosan, and Osaka, respectively. We should expect a higher correlation between lidar-measured linear particle depolarization ratios at $532 \mathrm{~nm}$ and the ones derived from AERONET at 675 and $440 \mathrm{~nm}$ as the lidar wavelength is be-
\end{abstract}

tween the two AERONET wavelengths. We cannot currently explain why we find better correlation between lidar and AERONET linear particle depolarization ratios for the case that the AERONET wavelengths $(675,870$, and $1020 \mathrm{~nm})$ are significantly larger than the lidar measurement wavelength $(532 \mathrm{~nm})$.

The linear particle depolarization ratio can be used as a parameter to obtain insight into the variation of optical and microphysical properties of dust when it is mixed with anthropogenic pollution particles. The single-scattering albedo increases with increasing measurement wavelength for low linear particle depolarization ratios, which indicates a high share of fine-mode anthropogenic pollution. In contrast, single-scattering albedo increases with increasing wavelength for high linear particle depolarization ratios, which indicated a high share of coarse-mode mineral dust particles. The retrieved volume particle size distributions are dominated by the fine-mode fraction if linear particle depolarization ratios are less than 0.15 at $532 \mathrm{~nm}$. The fine-mode fraction of the size distributions decreases and the coarsemode fraction of the size distribution increases for increasing linear particle depolarization ratio at $1020 \mathrm{~nm}$. The dust ratio based on using the linear particle depolarization ratio derived from AERONET data is 0.12 to 0.17 . These values are lower than the coarse-mode fraction derived from the volume con- 
centrations of particle size distributions, in which case we can compute the coarse-mode fraction of dust.

\section{Introduction}

There are various aerosol types of natural (primarily desert dust and sea salt) and anthropogenic (primarily combustion of biomass and fossil fuels) origin. A precise understanding of the radiative forcing of these aerosol types is the key to quantifying the aerosol impact on regional and global climate change (IPCC, 2013). In order to better estimate the aerosol effect (direct and indirect radiative forcing) on global climate change many studies have been performed with the goal of classifying aerosol types (Burton et al., 2013; Eck et al., 1999, 2010; Lee et al., 2010a; Dubovik et al., 2002). However, those studies do not separate aerosol types according to their contribution of mixed aerosols (respectively mixtures of different aerosol types) in a plume; they merely classify dominant aerosol types based on the optical properties of aerosols.

Dust is one of the major aerosol components in the atmosphere. Dust affects Earth's climate by interacting with solar as well as thermal infrared radiation. Dust also affects atmospheric dynamics, atmospheric chemistry, air quality, and ocean biogeochemistry over a wide range of spatial and temporal scales (e.g., Haywood et al., 2005; Jickells et al., 2005; Husar et al., 2001). On the global average, dust contributes to about one quarter of aerosol optical depth $(\tau)$ in the midvisible wavelength range (Kinne et al., 2006). Dust is also light absorbing (Lafon et al., 2004, 2006; Alfaro et al., 2004; Sokolik and Toon, 1999). It is estimated that more than half of aerosol absorption optical depth at $550 \mathrm{~nm}$ may come from dust (Chin et al., 2009).

The size distribution and absorption properties of desert dust and anthropogenic aerosols show properties that can be clearly distinguished (Russel et al., 2010; Dubovik et al., 2002). Desert dust predominately consists of coarse-mode particles (typical radius $>\sim 1 \mu \mathrm{m}$ ). In contrast, combustionproduced particles are predominately found in the finemode fraction of particle size distributions (typically radius $<\sim 1 \mu \mathrm{m}$ ). Aerosols in which fractions of fine-mode and coarse-mode particles are mixed are among the most challenging aerosol types to characterize. If we can separate desert dust from other aerosols in mixed dust plumes, we will improve our understanding of the effect those mixed aerosol plumes have on climate change.

The linear particle depolarization ratio $\left(\delta_{\mathrm{p}}\right)$ strongly depends on particle shape. Since dust particles have a nonspherical shape, the $\delta_{\mathrm{p}}$ can be used to identify the presence of dust particles in the atmosphere. In that regard lidar is a particularly powerful measurement technique (Shimizu et al., 2016; Tesche et al., 2009; Noh et al., 2007, 2008; Iwasaka et al., 2003; Cairo et al., 1999). The $\delta_{\mathrm{p}}$ has also been used to identify biogenic aerosols. Noh et al. (2013a, b) and Sassen et al. (2008) identified the vertical distribution of pollen in the atmosphere using the $\delta_{\mathrm{p}}$ measured by lidar. The possibility that dust particles are mixed with other, man-made pollution and/or biomass burning particles is very high, except in source regions of dust emissions where population density, and thus emissions caused by human activities are comparably low (Sun et al., 2005, 2010; Yu et al., 2006). Mixtures of dust particles and anthropogenic particles cause changes in the $\delta_{\mathrm{p}}$ of dust plumes. Shin et al. (2015) reported on lidar measurements and show that the $\delta_{\mathrm{p}}$ decreases when dust is mixed with pollution particles. The $\delta_{\mathrm{p}}$ is also a very useful parameter that allows us to separate dust from non-dust particles (anthropogenic, smoke, and sulfate particles) in mixed dust plumes by retrieving the dust ratio $\left(R_{\mathrm{D}}\right)$. Shimizu et al. (2004) estimated the contributions of dust and pollution particles in a mixed dust plume by the assumption that both aerosol types are externally mixed. The optical data of these mixed dust plumes were separated by the $R_{\mathrm{D}}$ into pure dust content and the contribution by anthropogenic particles (Noh et al., 2012b, 2016a; Bravo-Aranda et al., 2015; Noh, 2014). Tesche et al. (2011) separated the optical properties of desert dust and biomass burning particles in mixed dust and smoke plumes observed over the tropical North Atlantic, west of the African continent. The authors used multi-wavelength aerosol Raman lidar in combination with polarization lidar. Burton et al. (2014) provided a generalized version of the separation methodology between two aerosol types, i.e., urban pollution plus dust, marine plus dust, and smoke plus marine, by modifying the methodology suggested by Shimizu et al. (2004) and Tesche et al. (2011). Noh (2014) and Tesche et al. $(2009,2011)$ used the $\delta_{\mathrm{p}}$ to retrieve vertically resolved single-scattering albedo (SSA) of mixed dust plumes by separating the contribution of dust and non-dust particles. Ansmann et al. (2011) and Navas-Guzmán et al. (2013) separated the contribution of volcanic ash and sulfate particles to total backscatter and extinction coefficient by using the $\delta_{\mathrm{p}}$.

However, the number of lidar measurement sites is limited and provides rather sparse spatially resolved and temporally resolved information on the global scale. Thus, we need another methods that could allow us to measure $\delta_{\mathrm{p}}$.

AERONET (Aerosol Robotic NETwork) is an automated robotic sun-and-sky-scanning measurement network that took and still collects data at more than 797 measurement sites worldwide (http://aeronet.gsfc.nasa.gov/). These sites span everything from temporally limited observations at sites at which field campaigns were carried out to sites that carry out long-term observations since AERONET started with its observations. AERONET sun-sky radiometers provide globally distributed observations of spectrally resolved aerosol optical depth $(\tau)$ and data inversion products such as particle size distributions and complex refractive indices of different aerosol types (Holben et al., 1998).

Dubovik et al. (2006) suggested using AERONET sunsky radiometer data to retrieve $\delta_{\mathrm{p}}$. Müller et al. $(2010,2012)$ 
calculated the $\delta_{\mathrm{p}}$ of Saharan dust using AERONET sun-sky radiometer data. Noh et al. (2016b) and Lee et al. (2010b) used AERONET sun-sky radiometer data to retrieve the $\delta_{\mathrm{p}}$ of Asian dust. However, only cases of nearly pure desert dust particles were analyzed in these studies. There exist no studies in which the $\delta_{\mathrm{p}}$ for various mixtures (mixing ratio) between desert dust and anthropogenic pollution particles using AERONET data has been determined.

In this contribution we attempt to verify the reliability of AERONET-derived values of $\delta_{\mathrm{p}}$ by comparing these values to values of $\delta_{\mathrm{p}}$ measured by lidar.

Section 2 presents the methods used in this study. Section 3 presents our results. We discuss our results and summarize our findings in Sect. 4.

\section{Methodology}

\subsection{Study sites}

The AERONET sites considered in this study are all located along the pathway of the regime of prevailing westerly winds that serve as major transport routes of Asian dust, which is advected from the arid regions of China and Mongolia. Figure 1 shows the locations of the AERONET sun-sky radiometers and lidars used in this study.

Seoul $\left(37.45^{\circ} \mathrm{N}, 126.95^{\circ} \mathrm{E}\right)$ and Kongju $\left(36.47^{\circ} \mathrm{N}\right.$, $127.14^{\circ} \mathrm{E}$ ) are located inland (continental influenced), whereas Gosan $\left(33.29^{\circ} \mathrm{N}, 126.16^{\circ} \mathrm{E}\right)$ and Osaka $\left(34.65^{\circ} \mathrm{N}\right.$, $\left.135.59^{\circ} \mathrm{E}\right)$ are coastal sites. The Gosan site faces the Yellow Sea and is considered an ideal location for monitoring regional background aerosols in East Asia because there are few local industrial sources in that region. The other three sites are located inside large cities. We also use data from the AERONET site at Dunhuang $\left(40.49^{\circ} \mathrm{N}, 94.95^{\circ} \mathrm{E}\right)$ in our study, and we analyzed the depolarization ratios and optical properties of pure Asian dust at this source region.

Lidar data are obtained from the lidar network of the National Institute of Environmental Research (NIES), Japan. The lidars operated in this network are two-wavelength (1064 and $532 \mathrm{~nm}$ ) Mie-scattering lidars that also measure the linear particle depolarization ratio at $532 \mathrm{~nm}$. The details of these lidar systems and data processing procedures are explained by Shimizu et al. (2016) and Sugimoto et al. (2014).

The locations of the lidar systems used for our research work are the same as the locations of the AERONET systems for the sites in Seoul, Gosan, and Osaka. The lidar used for the Kongju site is located approximately $32 \mathrm{~km}$ to the northwest of the AERONET site.

\subsection{Depolarization ratios derived from data taken with AERONET sun-sky radiometer}

Dubovik et al. (2006) introduced kernel lookup tables that describe mixtures of spheroid particles. These kernel lookup tables were used to infer the $\delta_{\mathrm{p}}$ of mineral dust observed with

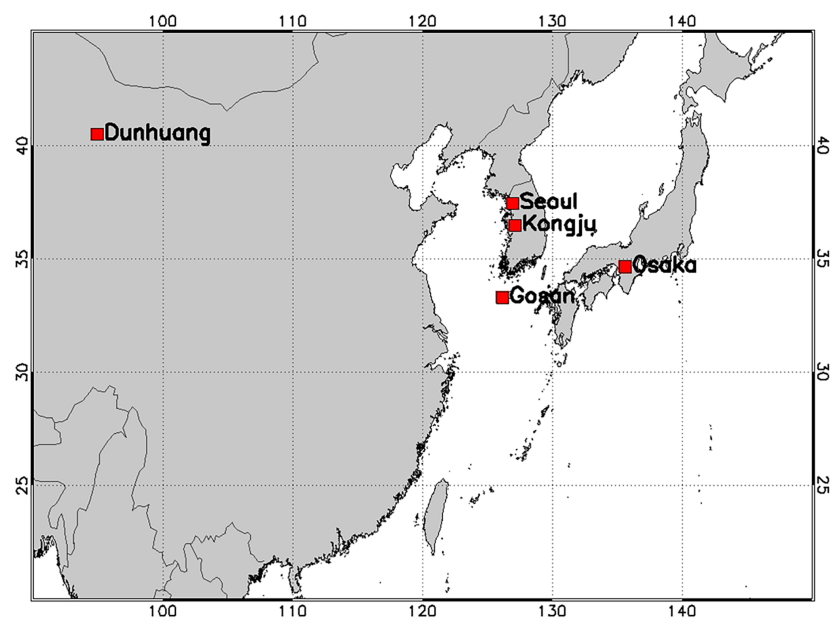

Figure 1. Map of the observation sites. Measurements with AERONET sun-sky radiometer and lidar were performed at Seoul, Kongju, Gosan, and Osaka. AERONET sun-sky radiometer measurements were made at Dunhuang.

sun-sky radiometer. The details of the AERONET inversion algorithm that processes data of mineral dust are given by Dubovik et al. (2006).

Briefly, the retrieval of the depolarization ratios works as follows. The elements $F_{11}(\lambda)$ and $F_{22}(\lambda)$ of the Müller scattering matrices (Bohren and Huffman, 1983) are computed from the retrieved complex refractive indices and particle size distributions. The term $F_{11}(\lambda)$ is proportional to the flux of the scattered light (Volten et al., 2001) in the case of unpolarized incident light. The $F_{22}(\lambda)$ term in turn follows from the angular and spectral distribution of the radiative intensity which is measured with the AERONET instrument (Dubovik et al., 2006). Another input parameter that is needed for the retrieval of $\delta_{\mathrm{p}}$ is the aspect ratio distribution. The aspect ratio indicates the ratio of a particle's longest axis to its shortest axis. In the case of prolate particles its polar diameter is greater than the equatorial diameter, in contrast to oblate particles where this ratio is vice versa. The aspect ratio distribution is kept to a fixed distribution in the AERONET model since scattering elements are nearly equivalent for all mixtures of spheroid particles (Dubovik et al., 2006).

From the ratio of the elements $F_{11}(\lambda)$ and $F_{22}(\lambda)$ at the scattering angle $180^{\circ}$ the $\delta_{\mathrm{p}}(\lambda)$ can be computed as

$\delta_{\mathrm{p}}(\lambda)=\frac{1-F_{22}\left(\lambda, 180^{\circ}\right) / F_{11}\left(\lambda, 180^{\circ}\right)}{1+F_{22}\left(\lambda, 180^{\circ}\right) / F_{11}\left(\lambda, 180^{\circ}\right)}$.

The $\delta_{\mathrm{P}}$ derived from the sun-sky radiometer data is written as $\delta_{\mathrm{P}}^{\mathrm{S}}$ so that we can distinguish it from the lidar-derived $\delta_{\mathrm{P}}$, i.e., $\delta_{\mathrm{P}}^{\mathrm{L}}$.

The contributions of dust and anthropogenic pollution particles to the total backscatter coefficients of mixed aerosol plumes were estimated from the $\delta_{\mathrm{P}}$ under the assumption that both types of aerosol particles are externally mixed. The dust 
ratio $\left(R_{\mathrm{D}}\right)$ of the dust-related backscatter coefficient to the total backscatter coefficient was calculated using Eq. (1), based on the method suggested by Shimizu et al. (2004):

$R_{\mathrm{D}}=\frac{\left(\delta_{\mathrm{P}}^{\mathrm{S}}-\delta_{2}\right)\left(1+\delta_{1}\right)}{\left(\delta_{1}-\delta_{2}\right)\left(1+\delta_{\mathrm{P}}^{\mathrm{S}}\right)}$,

where $\delta_{1}$ and $\delta_{2}$ denote the $\delta_{\mathrm{P}}^{\mathrm{S}}$ of pure dust and non-dust particles (i.e., the total aerosol plume without the contribution by dust), respectively, in the external mixture of aerosol particles. The values $\delta_{1}$ and $\delta_{2}$ can be empirically determined. In the present study, we used the value 0.34 for $\delta_{1}$. This value was derived from adding 0.01 to the maximum value observed at the Dunhuang site (Asian dust source region). The value of 0.02 was used for $\delta_{2}$, which is the minimum value used in this study. When $\delta_{\mathrm{P}}^{\mathrm{S}}$ was higher than $\delta_{1}$ or lower than $\delta_{2}, R_{\mathrm{D}}$ was set to 1 or 0 , respectively.

Two kinds of coarse-mode fractions (CMFs) were calculated. The CMF of the aerosol optical depth $(\tau)(\mathrm{CMF} \tau)$ is calculated from the ratio of the coarse-mode $\tau$ to the total (coarse + fine mode) $\tau$ at the same wavelength at which the $\delta_{\mathrm{P}}^{\mathrm{S}}$ is available. The CMF is also calculated on the basis of the volume concentration $\left(\mathrm{CMF}_{\mathrm{vc}}\right)$.

\subsection{Column-integrated depolarization ratio measured by lidar}

The lidar systems used in our study measure the linear volume depolarization ratio (aerosols + molecules; $\delta^{\mathrm{L}}$ ) from the linearly and perpendicularly polarized components of the Mie-Rayleigh backscatter signals at $532 \mathrm{~nm}$ wavelength (Shimizu et al., 2004). The value of $\delta^{\mathrm{L}}$ is defined as

$\delta^{\mathrm{L}}(z)=\frac{P_{\perp}(z)}{P_{\|}(z)}$,

where $P(z)$ is the backscatter signal with respect to height $z$. The symbols $\|$ and $\perp$ denote the linearly and perpendicularly polarized components with respect to the plane of polarization of the emitted laser light, respectively.

In order to obtain reliable depolarization ratios, the data of the lidar measurements must be calibrated before physical quantities such as the linear volume depolarization ratio can be retrieved. It is important to calibrate the signal intensities of the $P_{\|}$and $P_{\perp}$ first, before the linear volume depolarization ratio is calculated. The calibration method of the lidar system is explained in detail by Shimizu et al. (2016) and Nishizawa et al. (2017).

The difference of the sensitivity between two photomultiplier tubes (PMTs) that are used by the lidar system to detect these components is checked regularly by the following method. A sheet polarizer whose polarizing direction is set at $45^{\circ}$ to the polarizing plane of the emitted light is inserted in front of the beam splitter cube, and the backscatter signal from the sky is recorded as a reference signal. In this reference record, the light intensities of the two channels are equal after the sheet polarizer, so the calibration constant can be obtained by comparing the recorded values of $P_{\|}$and $P_{\perp}$. In the next step, the sheet polarizer is rotated by $90^{\circ}$, which sets the polarizing angle at $-45^{\circ}$, and another reference signal is recorded. Then relative calibration of $P_{\|}$and $P_{\perp}$ channels is performed using signals measured for the polarizing angles at $\pm 45^{\circ}$. This pair of reference signals reduces any error caused by a poor positioning of the sheet polarizer (Freudenthaler et al., 2009, 2016). The reference signals are usually recorded once per year for each lidar (Shimizu et al., 2016).

A different definition of the $\delta^{\mathrm{L}}\left(\delta^{\mathrm{LT}}=P_{\perp} /\left(P_{\|}+P_{\perp}\right)\right)$ is used in many other studies, e.g., Noh et al. (2016a, 2013b) and Sakai et al. (2000). The term $\delta^{L T}$ is defined differently from the definition we use for $\delta^{\mathrm{L}}$ in our work. It is expressed by the following equation, derived from Eq. (3) (see Cairo et al., 1999).

$\delta^{\mathrm{LT}}=\frac{\delta^{\mathrm{L}}}{\delta^{\mathrm{L}}+1}$

The variable $\delta_{\mathrm{P}}^{\mathrm{L}}$ differs from $\delta^{\mathrm{L}}$ as it depends on the concentration of particles and it does not take account of the contribution (concentration) of air molecules. In this contribution, $\delta_{\mathrm{P}}^{\mathrm{L}}$ can be calculated on the basis of the definition provided by Sakai et al. (2003):

$\delta_{\mathrm{P}}^{\mathrm{L}}(z)=\frac{\delta^{\mathrm{L}}(z)\left(R(z)+R(z) \times \delta_{\mathrm{M}}-\delta_{\mathrm{M}}\right)-\delta_{\mathrm{M}}}{R(z)-1+R(z) \times \delta_{\mathrm{M}}-\delta^{\mathrm{L}}(z)}(\%)$.

The backscatter ratio $R$ is the ratio of the sum of the aerosol backscatter coefficient $\left(\beta_{\mathrm{P}}+\beta_{\mathrm{M}}\right)$ to the pure molecular backscatter coefficient $\left(\beta_{\mathrm{M}}\right)$, which, according to Whiteman et al. (1992) can be expressed by

$R(z)=\frac{\beta_{\mathrm{P}}(z)+\beta_{\mathrm{M}}(z)}{\beta_{\mathrm{M}}(z)}$.

$\beta_{\mathrm{P}}$ and $\beta_{\mathrm{M}}$ are the volume backscatter coefficients of aerosol particles and air molecules, respectively. The molecular depolarization ratio $\left(\delta_{\mathrm{M}}\right)$ is assumed to be 0.014 (Shimizu et al., 2004).

The parameter $\delta_{\mathrm{P}}^{\mathrm{L}}$ can be derived by lidar measurements in terms of vertical profiles. In contrast, $\delta_{\mathrm{P}}^{\mathrm{S}}$ describes a columnintegrated value. For that reason, $\delta_{\mathrm{P}}^{\mathrm{L}}$ had to be changed to column-integrated values in our study so that we could carry out a direct comparison with $\delta_{\mathrm{P}}^{\mathrm{S}}$.

The column-integrated and weighted values of $\delta_{\mathrm{P}}^{\mathrm{L}}\left(\delta_{\mathrm{P}}^{\mathrm{CL}}\right)$ can be calculated by

$\left.\delta_{\mathrm{P}}^{\mathrm{CL}}=\int_{0}^{z} \delta_{\mathrm{P}}^{\mathrm{L}} z\right) W(z) \mathrm{d} z$,

where the term $W(z)$ is a weight factor that is calculated by using the measured aerosol backscatter coefficient $\left(\beta_{\mathrm{P}}\right)$ according to

$W(z)=\frac{\beta_{\mathrm{P}}(z)}{\int_{0}^{z} \beta_{\mathrm{P}}(z) \mathrm{d} z}$. 
The aerosol backscatter coefficient is derived by the backward version of Fernald's method (Fernald, 1984). The data observed at $9 \mathrm{~km}$ height are used as reference height for the analysis of data taken under cloud-free conditions.

The reference height is lowered if the signal-to-noise ratio at $9 \mathrm{~km}$ is not sufficient, which may be the case of high aerosol concentration. Molecular density profiles are taken from the COSPAR international reference atmosphere (CIRA-86) for computing the Rayleigh scattering component. A constant lidar ratio of $50 \mathrm{sr}$ is applied in the calculation of the aerosol backscatter coefficients (Shimizu et al., 2016). Since the lidar ratio differs for different aerosol types, the selection of the lidar ratio is important to obtain exact values of extinction and backscatter coefficients. However, we only use the ratio of the backscatter coefficient in the calculation of $W(z)$ in our study. For that reason, the value of the lidar ratio does not affect the calculation of $W(z)$.

Figure 2 shows a retrieval example of $\delta_{\mathrm{P}}^{\mathrm{CL}}$. Three cases, corresponding to lidar measurements carried out at 23:00 UTC (start time of measurement) on 13 March 2010 (Fig. 2a), at 06:00 UTC on 22 March 2010 (Fig. 2b), and at 23:15 UTC on 3 May 2010 (Fig. 2c), are shown. The measurement on 13 March 2010 describes an aerosol plume that has a high value of $\delta_{\mathrm{P}}^{\mathrm{L}}$ and a high value of $\beta_{\mathrm{P}}$ (case 1, Fig. 2a). The measurement on 22 March 2010 describes an aerosol plume with high $\beta_{\mathrm{P}}$ below and above the planetary boundary layer (PBL), respectively. However, a high value of $\delta_{\mathrm{P}}^{\mathrm{L}}$ is detected above the PBL (case 2, Fig. 2b) only. The measurement on 2 May 2010 describes an aerosol plume with low backscatter coefficients and a high value of $\delta_{\mathrm{P}}^{\mathrm{L}}$ (case 3, Fig. 2c). The averaged values of $\delta_{\mathrm{P}}^{\mathrm{L}}\left(\delta_{\mathrm{ave}}\right)$ which do not consider the backscatter intensity but just the averaged $\delta_{\mathrm{P}}^{\mathrm{L}}$ from the bottom to the top height of the profiles of $\delta_{\mathrm{P}}^{\mathrm{L}}$ are listed in Fig. 2, too.

The values of $\delta_{\mathrm{P}}^{\mathrm{S}}$ at $1020 \mathrm{~nm}$ are $0.250,0.140$, and 0.164 for the cases 1-3, respectively. The values of $\delta_{\mathrm{P}}^{\mathrm{CL}}$ are similar to the values of $\delta_{\mathrm{P}}^{\mathrm{S}}$. We find $0.243,0.129$, and 0.157 for the cases $1-3$, respectively. However, the values of $\delta_{\text {ave }}$ for case 1 and case 3 are different compared to the values of $\delta_{\mathrm{P}}^{\mathrm{S}}$. Since $\delta_{\mathrm{P}}^{\mathrm{L}}$ is not directly related to aerosol concentration but only to the non-sphericity of (an ensemble of) aerosol particles (inside a given volume of air) large values of $\delta_{\mathrm{P}}^{\mathrm{L}}$ can occur for high as well as for low aerosol backscatter coefficients. Lower values of $\delta_{\mathrm{ave}}$ compared to $\delta_{\mathrm{P}}^{\mathrm{S}}$ are linked to high values of $\delta_{\mathrm{P}}^{\mathrm{L}}$ for the case of high aerosol backscatter coefficients of a thin aerosol layer (see Fig. 2a). We find that the value of $\delta_{\text {ave }}$ is higher than the value of $\delta_{\mathrm{P}}^{\mathrm{S}}$ for the situation in which a high value of $\delta_{\mathrm{P}}^{\mathrm{L}}$ is combined with a low aerosol backscatter coefficient (see Fig. 2c). The examples in Fig. 2 show that $\delta_{\mathrm{P}}^{\mathrm{CL}}$ has to be compared with $\delta_{\mathrm{P}}^{\mathrm{S}}$.

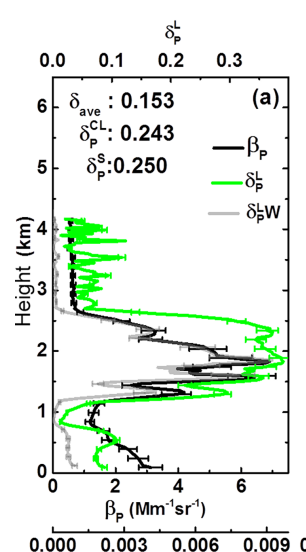

$\delta_{\mathrm{p}}^{\mathrm{L} W}$ (A.U.)

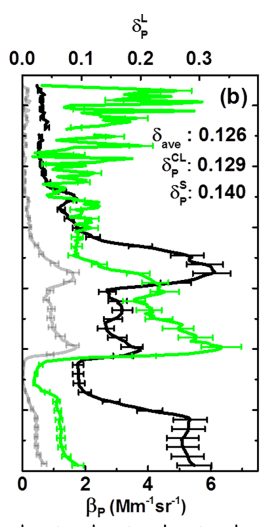

$\delta_{\mathrm{p}}^{\mathrm{L} W}$ (A.U.)

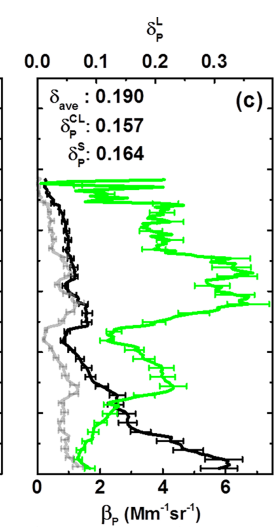

$\beta_{\mathrm{P}}\left(\mathrm{Mm}^{-1} \mathrm{sr}^{-1}\right)$
Figure 2. Lidar-derived aerosol backscatter coefficient $\left(\beta_{\mathrm{P}}\right.$; black line), the linear particle depolarization ratio $\left(\delta_{\mathrm{P}}^{\mathrm{L}}\right.$; green $)$, and the weighted linear particle depolarization ratio $\left(\delta_{\mathrm{P}}^{\mathrm{LW}}\right.$; gray $)$ at $532 \mathrm{~nm}$ observed (a) from 23:00 to 23:15 UTC on 13 March 2010, (b) from 06:00 to 06:15 UTC on 22 March 2010, and (c) from 23:15 to 23:30 UTC on 3 May 2010. The wavelength of $\delta_{\mathrm{P}}^{\mathrm{S}}$ is $1020 \mathrm{~nm}$. The height is expressed as altitude above ground level (a.g.l.).

\section{Results and discussion}

\subsection{AERONET-derived depolarization ratios and lidar-measured values: comparison}

Figure 3 shows the temporal variation of $\tau$ at $500 \mathrm{~nm}$ and the values of $\delta_{\mathrm{P}}^{\mathrm{S}}$ at $1020 \mathrm{~nm}$ at the four AERONET sites. The combined data of the four sites are shown in the same figure. The number of measurement cases for the four sites is listed in Table 1 . The total number of retrieved values of $\delta_{\mathrm{P}}^{\mathrm{S}}$ is $163,44,139$, and 234 at Seoul, Kongju, Gosan, and Osaka, respectively. Since the measurement cases are limited it is difficult to analyze seasonal trends. However, we find high values of $\tau$ and $\delta_{\mathrm{P}}^{\mathrm{S}}$ in spring (March to May). We assume that these high values are caused by transport of dust from East Asia to the Pacific Ocean.

Figure 4 presents scatterplots of $\delta_{\mathrm{P}}^{\mathrm{CL}}$ and $\delta_{\mathrm{P}}^{\mathrm{S}}$ at the four AERONET sites. We compare the values of the $\delta_{\mathrm{P}}^{\mathrm{S}}$ at these four wavelengths $(440,675,870$, and $1020 \mathrm{~nm})$ to the values of $\delta_{\mathrm{P}}^{\mathrm{CL}}$ at $532 \mathrm{~nm}$. The correlation coefficients $R^{2}$ at $1020 \mathrm{~nm}$ are high. We find 0.90, 0.92, 0.79, and 0.89 at Seoul, Kongju, Gosan, and Osaka, respectively.

We find similarly high correlation between $\delta_{\mathrm{P}}^{\mathrm{CL}}$ and $\delta_{\mathrm{P}}^{\mathrm{S}}$ at $870 \mathrm{~nm}$, i.e., numbers are $0.89,0.92,0.76$, and 0.88 at Seoul, Kongju, Gosan, and Osaka, respectively. The correlation at $675 \mathrm{~nm}$ is lower than the values we find at 870 and $1020 \mathrm{~nm}$. Values are 0.81, 0.90, 0.64, and 0.81 at Seoul, Kongju, Gosan, and Osaka, respectively. The correlation is significantly low at $440 \mathrm{~nm}$. Values are $0.38,0.62,0.26$, and 0.28 at Seoul, Kongju, Gosan, and Osaka, respectively. 


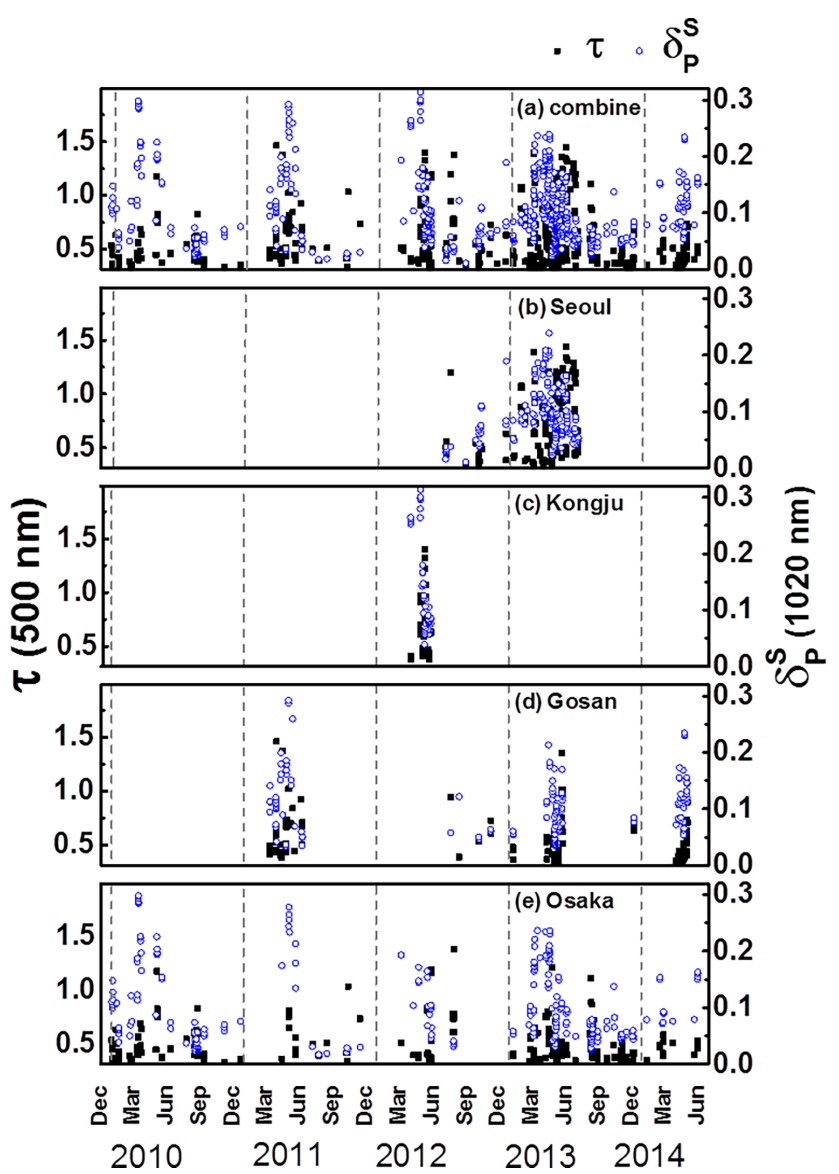

Figure 3. Aerosol optical depth $(\tau)$ at $500 \mathrm{~nm}$ retrieved from AERONET sun-sky radiometer measurements (black squares) and linear particle depolarization ratio derived at $1020 \mathrm{~nm}$ from sunsky radiometer data $\left(\delta_{\mathrm{P}}^{\mathrm{S}}\right.$; blue open circles). (a) Data of the four sites taken from 2010 to 2014; (b) data taken at Seoul for two years (2012 and 2013); (c) data taken at Kongju in spring 2012; (d) data taken at Gosan during four years (2011-2014), mostly during spring; (e) data taken from 2010 to 2014 at Osaka.

The correlation coefficient at $440 \mathrm{~nm}$ at Kongju is much higher than at the other sites. This higher correlation may be caused by the limited number of observational data and/or observation times. Only 44 cases were taken during a short period of 2 months, from April to May 2012 at Kongju.

Figure 4 shows that the differences between $\delta_{\mathrm{P}}^{\mathrm{CL}}$ and $\delta_{\mathrm{P}}^{\mathrm{S}}$ are high when the value of $\delta_{\mathrm{P}}^{\mathrm{CL}}$ is less than 0.10 at Seoul, Gosan and Osaka. However, the number of cases of low $\delta_{\mathrm{P}}^{\mathrm{CL}}$ $(<0.10)$ is comparably low at Kongju compared to the other sites. The number of cases with high $\delta_{\mathrm{P}}^{\mathrm{CL}}(>0.25)$ is comparably high (with respect to all cases), i.e., $23 \%$ (10 cases out of 44 in total), compared to what we find for the other sites: 0/163, 3/139, and 10/234 at Seoul, Gosan, and Osaka, respectively (see Table 1).

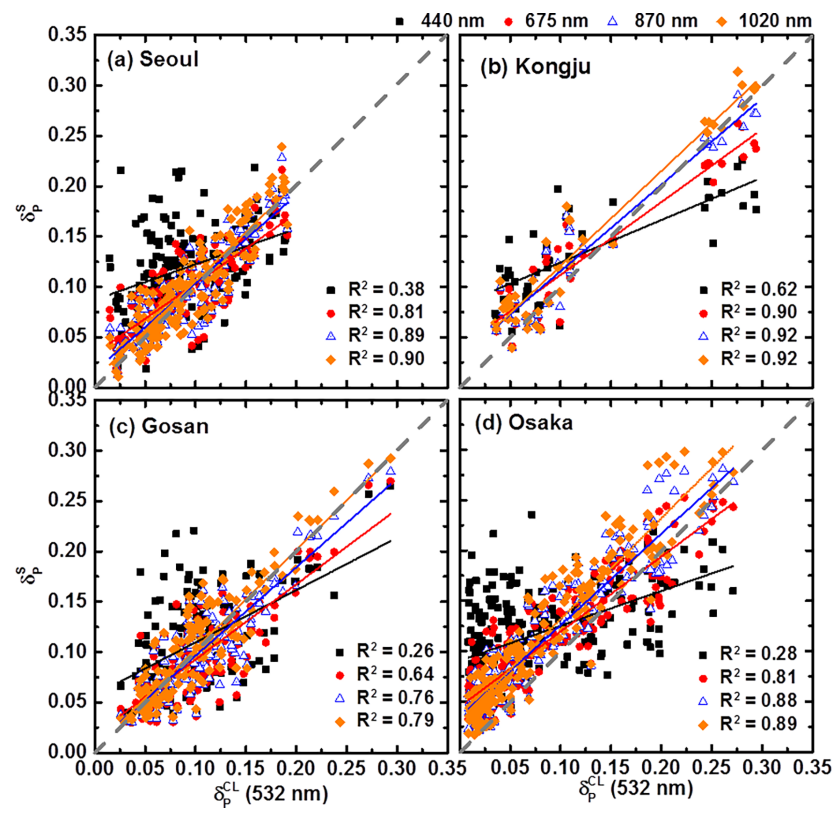

Figure 4. The correlation coefficients $R^{2}$ (the coefficient of determination) between $\delta_{\mathrm{P}}^{\mathrm{CL}}$ at 532 and $\delta_{\mathrm{P}}^{\mathrm{S}}$ at 440 (black squares), 675 (red circles), 870 (blue open triangles), and $1020 \mathrm{~nm}$ (orange diamonds) at (a) Seoul, (b) Kongju, (c) Gosan, and (d) Osaka.

We tried to find the reason for the comparably low correlation at $440 \mathrm{~nm}$. For that reason, we retrieved the $\delta_{\mathrm{P}}^{\mathrm{S}}$ at $532 \mathrm{~nm}$ by interpolating the value of $\delta_{\mathrm{P}}^{\mathrm{S}}$ at $532 \mathrm{~nm}$ on the basis of the four AERONET wavelengths. In the next step the differences between $\delta_{\mathrm{P}}^{\mathrm{S}}$ and $\delta_{\mathrm{P}}^{\mathrm{CL}}$ at $532 \mathrm{~nm}\left(\delta_{\mathrm{P}, 532}^{\mathrm{CL}}-\delta_{\mathrm{P}, 532}^{\mathrm{S}}\right)$ were calculated by deducting $\delta_{\mathrm{P}}^{\mathrm{CL}}$ (at $532 \mathrm{~nm}$ ) from $\delta_{\mathrm{P}}^{\mathrm{S}}$ (at $532 \mathrm{~nm}$ ) for all 580 cases for which we have $\delta_{\mathrm{P}}^{\mathrm{S}}$ at the four AERONET sites.

The values $\delta_{\mathrm{P}, 532}^{\mathrm{CL}}-\delta_{\mathrm{P}, 532}^{\mathrm{S}}$ of were varied from 0.14 to -0.09 . In the following step the data were sorted according to the differences of $\delta_{\mathrm{P}, 532}^{\mathrm{CL}}-\delta_{\mathrm{P}, 532}^{\mathrm{S}}$. In the final step we divided these differences into intervals of 0.02 , i.e., $1>0.12,20.10-0.12,30.08-0.10, \ldots, 11-0.06-$ $(-0.08), 12<(-0.08)$.

Figure 5 shows the variation of the averaged $\delta_{\mathrm{P}}^{\mathrm{S}}$ at the five wavelengths and the values of $\delta_{\mathrm{P}}^{\mathrm{CL}}$ at $532 \mathrm{~nm}$ divided by the differences of $\delta_{\mathrm{P}, 532}^{\mathrm{CL}}-\delta_{\mathrm{P}, 532}^{\mathrm{S}}$. The differences of $\delta_{\mathrm{P}}^{\mathrm{S}}$ between the wavelengths at 440 and $1020 \mathrm{~nm}$ are high.

We find that $\delta_{\mathrm{P}}^{\mathrm{S}}$ decreases with increasing wavelength if the value of $\delta_{\mathrm{P}, 532}^{\mathrm{CL}}-\delta_{\mathrm{P}, 532}^{\mathrm{S}}$ is low. The differences between $\delta_{\mathrm{P}}^{\mathrm{S}}$ at $440 \mathrm{~nm}$ and $\delta_{\mathrm{P}}^{\mathrm{S}}$ at $1020 \mathrm{~nm}$ become less for increasing interval number, i.e., $\delta_{\mathrm{P}, 532}^{\mathrm{CL}}-\delta_{\mathrm{P}, 532}^{\mathrm{S}}$ for the interval number $7(0-$ 0.02) (i.e., the yellow triangle pointing to the right in Fig. 5). The value of $\delta_{\mathrm{P}}^{\mathrm{CL}}$ at $532 \mathrm{~nm}$ shows lower values than $\delta_{\mathrm{P}}^{\mathrm{S}}$ at $1020 \mathrm{~nm}$ in those intervals. The differences between $\delta_{\mathrm{P}}^{\mathrm{CL}}$ at $532 \mathrm{~nm}$ and $\delta_{\mathrm{P}}^{\mathrm{S}}$ at $1020 \mathrm{~nm}$ are reduced as $\delta_{\mathrm{P} .532}^{\mathrm{CL}}-\delta_{\mathrm{P} .532}^{\mathrm{S}}$ is decreased up to the interval number $7(0-0.02)$. We find an increase of $\delta_{\mathrm{P}}^{\mathrm{S}}$ with increasing wavelength from the interval 


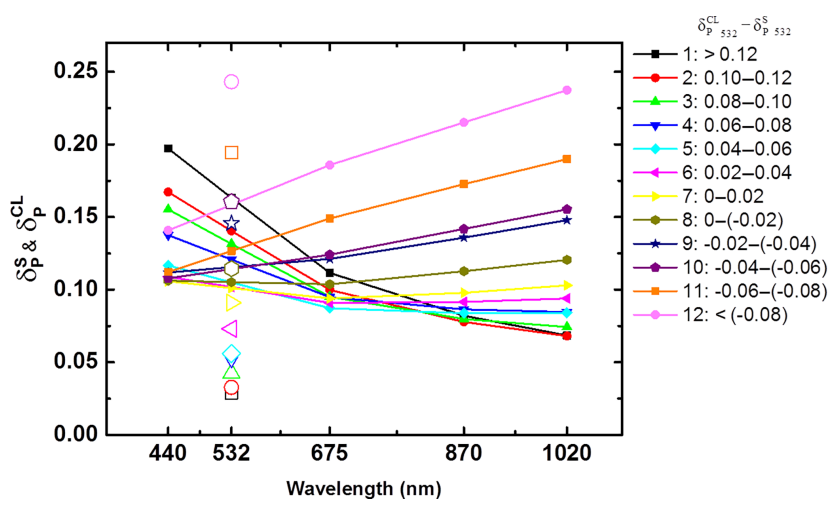

Figure 5. The average values of $\delta_{\mathrm{P}}^{\mathrm{S}}$ at five wavelengths (440, 532, $670,875$, and $1020 \mathrm{~nm})$ and $\delta_{\mathrm{P}}^{\mathrm{CL}}$ at $532 \mathrm{~nm}$ divided by the range of the differences between $\delta_{\mathrm{P}}^{S}$ and $\delta_{\mathrm{P}}^{\mathrm{CL}}$ at $532 \mathrm{~nm}\left(\delta_{\mathrm{P}, 532}^{\mathrm{CL}}-\delta_{\mathrm{P}, 532}^{\mathrm{S}}\right)$. The symbol of $\delta_{\mathrm{P}}^{\mathrm{CL}}$ at $532 \mathrm{~nm}$ is shown as open figure and in larger size.

number $8(0-(-0.02))$. The value of $\delta_{\mathrm{P}}^{\mathrm{CL}}$ at $532 \mathrm{~nm}$ is larger than the value of $\delta_{\mathrm{P}}^{\mathrm{S}}$ at $1020 \mathrm{~nm}$ in the interval number $8(0-$ $(-0.02))$. Also, the differences between $\delta_{\mathrm{P}}^{\mathrm{CL}}$ at $532 \mathrm{~nm}$ and $\delta_{\mathrm{P}}^{\mathrm{S}}$ at $1020 \mathrm{~nm}$ are increased as the interval number increased.

If we assume that the value of $\delta_{\mathrm{P}}^{\mathrm{CL}}$ at $532 \mathrm{~nm}$ is close to real value of $\delta_{\mathrm{P}}$, the results in Fig. 5 indicate that the $\delta_{\mathrm{P}}^{\mathrm{S}}$ at $440 \mathrm{~nm}$ has been retrieved to be higher value than the $\delta_{\mathrm{P}}^{\mathrm{CL}}$ at $532 \mathrm{~nm}$ in the interval number from $1(>0.12)$ to $7(0-0.02)$ when the $\delta_{\mathrm{P}}^{\mathrm{CL}}$ at $532 \mathrm{~nm}$ showed low values (less than 0.08). Conversely, when the high $\delta_{\mathrm{P}}^{\mathrm{CL}}$ at $532 \mathrm{~nm}$ was measured, the $\delta_{\mathrm{P}}^{\mathrm{S}}$ at $440 \mathrm{~nm}$ showed a lower value than the $\delta_{\mathrm{P}}^{\mathrm{CL}}$ at $532 \mathrm{~nm}$.

Figure 6 shows the average of volume particle size distributions of each interval data as separated in Fig. 5. We see that the volume size distributions change from fine-mode-dominated size distributions to coarse-modedominated size distributions when the interval number moves from $1(>0.12)$ to $12(<(-0.08))$.

The important point of Fig. 6 is the variation of the volume median radius $(\mathrm{Rv})$. The volume median radius of the coarse $\left(R v_{c}\right)$ and the fine $\left(R v_{f}\right)$ mode shows a maximum value at the interval number $1(>0.12) . R v_{f}$ clearly and progressively decreases as the interval number moves from $1(>0.12)$ to $12(<(-0.08))$. The $\mathrm{Rv}_{\mathrm{f}}$ of the interval number $1(>0.12)$ is 2 times larger than the interval number of $12(<(-0.08))$ as $0.28 \pm 0.03$ and $0.13 \pm 0.01 \mu \mathrm{m}$, respectively. $\mathrm{Rv}_{\mathrm{c}}$ also shows a pattern of decreasing values with decreasing values of $\delta_{\mathrm{P}, 532}^{\mathrm{CL}}-\delta_{\mathrm{P}, 532}^{\mathrm{S}}$, but it does not show as progressively as $\mathrm{Rv}_{\mathrm{f}}$.

Figures 5 and 6 show that the value of $\delta_{\mathrm{P}}^{\mathrm{S}}$ at $440 \mathrm{~nm}$ tends to be retrieved high for conditions where there is no dust at all or the dust concentration is low. Such conditions are usually dominated by a significant fine mode of the particle size distribution.

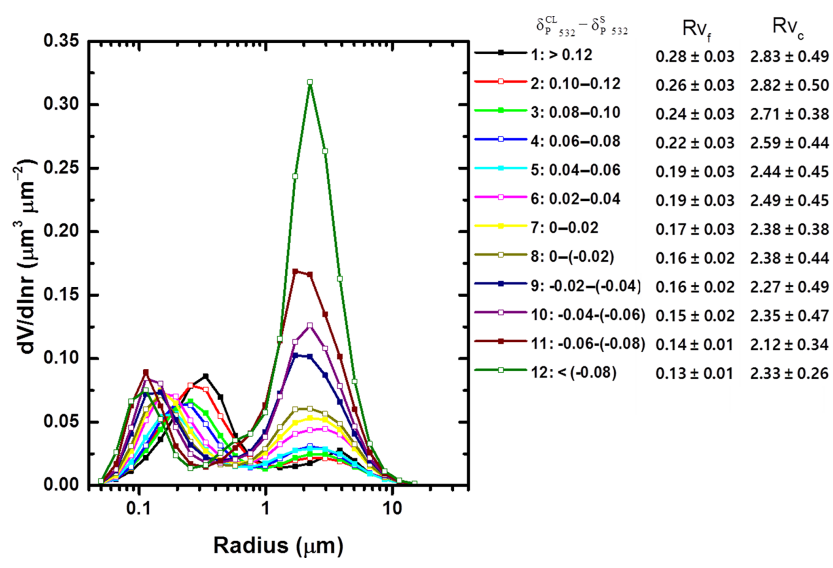

Figure 6. The average value of the volume size distributions derived by AERONET sun-sky radiometer measurements divided by the range of the differences between $\delta_{\mathrm{P}}^{\mathrm{S}}$ and $\delta_{\mathrm{P}}^{\mathrm{CL}}$ at $532 \mathrm{~nm}$ $\left(\delta_{\mathrm{P}, 532}^{\mathrm{CL}}-\delta_{\mathrm{P}, 532}^{\mathrm{S}}\right)$.

When dust particles contribute the main share to the particle concentration, i.e., high values of $\delta_{\mathrm{P}}^{\mathrm{CL}}$ at $532 \mathrm{~nm}$, the contribution of fine-mode particles is small. When particles in the fine mode are the main contribution of the particle size distribution, i.e., low values of $\delta_{\mathrm{P}}^{\mathrm{CL}}$ at $532 \mathrm{~nm}$, the size of the particles in the fine-mode fraction are considered to have a large influence on the retrieval of the values of $\delta_{\mathrm{P}}^{\mathrm{S}}$. This effect is considered to be more significant at $440 \mathrm{~nm}$, i.e., at short wavelengths.

Mamouri and Ansmann (2017) found that the value of $\delta_{\mathrm{P}}^{\mathrm{L}}$ is maximum at $532 \mathrm{~nm}$ and lower at 355 and $1064 \mathrm{~nm}$ because of the competing influence the fine-mode and coarsemode dust fraction have on the overall values (fine + coarse) of $\delta_{\mathrm{P}}^{\mathrm{L}}$ at the three wavelengths.

Haarig et al. (2017) found that on average the values of $\delta_{\mathrm{P}}^{\mathrm{L}}$ for aged Saharan dust were 0.25 at $355 \mathrm{~nm}, 0.31$ at $532 \mathrm{~nm}$, and 0.225 at $1064 \mathrm{~nm}$. Müller et al. (2010, 2012) and Freudenthaler et al. (2009) also found spectral slope of the depolarization ratio with the maximum at $532 \mathrm{~nm}$ and lower values at 355 and $1064 \mathrm{~nm}$ during the 2006 Saharan Mineral Dust Experiment (SAMUM). The results clearly show a different pattern of the spectral variations of $\delta_{\mathrm{P}}$ measured by lidar and retrieved from sun-sky radiometer observations of dust.

It is a striking result that $\delta_{\mathrm{P}}^{\mathrm{S}}$ at $1020 \mathrm{~nm}$, unlike $\delta_{\mathrm{P}}^{\mathrm{S}}$ at $440 \mathrm{~nm}$, is very similar to the values of $\delta_{\mathrm{P}}^{\mathrm{CL}}$ at $532 \mathrm{~nm}$. Though we cannot identify the reason for this similarity and - even if the wavelengths (lidar at $532 \mathrm{~nm}$ and AERONET sun-sky radiometer at $1020 \mathrm{~nm}$ ) are different - we may use the values of $\delta_{\mathrm{P}}^{\mathrm{S}}$ at $1020 \mathrm{~nm}$ as a qualitative indicator of the presence of mineral dust particles in the atmosphere. It remains to be seen whether we can use this parameter also as a qualitative measure of the mixing ratio of mineral dust and anthropogenic pollution particles compared to the more robust parameter $\delta_{\mathrm{P}}^{\mathrm{CL}}$ (at $532 \mathrm{~nm}$ ). 
Table 1. Average value of aerosol optical depth $(\tau)$ at $500 \mathrm{~nm}$, optical-depth-related Ångström exponent $(\AA \AA$, $440-870 \mathrm{~nm})$, absorption-related Ångström exponent $\left(\AA_{\mathrm{A}}\right)$, dust ratio $\left(R_{\mathrm{D}}\right)$ derived by $\delta_{\mathrm{P}}^{\mathrm{S}}$ at $1020 \mathrm{~nm}$, coarse-mode fraction of the $\tau$ at $1020 \mathrm{~nm}\left(\mathrm{CMF}_{\tau}\right)$, coarse-mode fraction of the volume concentration $\left(\mathrm{CMF}_{\mathrm{vc}}\right)$, and difference between $\mathrm{CMF}_{\mathrm{vc}}$ and $R_{\mathrm{D}}\left(\mathrm{CMF}_{\mathrm{vc}}-R_{\mathrm{D}}\right)$.

\begin{tabular}{|c|c|c|c|c|c|c|c|c|}
\hline & $\begin{array}{l}\delta_{\mathrm{P}}^{\mathrm{S}} \\
(1020 \mathrm{~nm})\end{array}$ & $\begin{array}{r}\text { Group } 1 \\
0-0.05\end{array}$ & $\begin{array}{c}\text { Group } 2 \\
0.05-0.1\end{array}$ & $\begin{array}{c}\text { Group } 3 \\
0.1-0.15\end{array}$ & $\begin{array}{r}\text { Group } 4 \\
0.15-0.2\end{array}$ & $\begin{array}{r}\text { Group } 5 \\
0.2-0.25\end{array}$ & $\begin{array}{c}\text { Group } 6 \\
0.25>\end{array}$ & Total \\
\hline \multirow{8}{*}{ Seoul } & No. & 25 & 74 & 38 & 21 & 5 & & 163 \\
\hline & $\tau(500 \mathrm{~nm})$ & $0.62 \pm 0.26$ & $0.74 \pm 0.31$ & $0.77 \pm 0.29$ & $0.62 \pm 0.25$ & $0.89 \pm 0.29$ & & $0.72 \pm 0.29$ \\
\hline & $\AA$ & $1.42 \pm 0.21$ & $1.38 \pm 0.16$ & $1.22 \pm 0.16$ & $1.05 \pm 0.12$ & $0.8 \pm 0.15$ & & $1.29 \pm 0.22$ \\
\hline & $\AA_{\mathrm{A}}$ & $1.32 \pm 0.37$ & $1.56 \pm 0.43$ & $1.78 \pm 0.40$ & $1.8 \pm 0.29$ & $1.88 \pm 0.36$ & & $1.62 \pm 0.43$ \\
\hline & $R_{\mathrm{D}}$ & $0.08 \pm 0.04$ & $0.22 \pm 0.05$ & $0.37 \pm 0.05$ & $0.51 \pm 0.05$ & $0.63 \pm 0.05$ & & $0.29 \pm 0.15$ \\
\hline & $\mathrm{CMF} \tau^{*}$ & $0.13 \pm 0.06$ & $0.29 \pm 0.14$ & $0.46 \pm 0.12$ & $0.69 \pm 0.06$ & $0.78 \pm 0.02$ & & $0.37 \pm 0.21$ \\
\hline & $\mathrm{CMF}_{\mathrm{Vc}}$ & $0.22 \pm 0.06$ & $0.38 \pm 0.11$ & $0.56 \pm 0.09$ & $0.70 \pm 0.05$ & $0.79 \pm 0.06$ & & $0.45 \pm 0.18$ \\
\hline & $\mathrm{CMF}_{\mathrm{vc}}-R_{\mathrm{D}}$ & 0.14 & 0.16 & 0.19 & 0.19 & 0.16 & & 0.16 \\
\hline \multirow{8}{*}{ Kongju } & No. & 1 & 22 & 8 & 3 & & 10 & 44 \\
\hline & $\tau(500 \mathrm{~nm})$ & 0.67 & $0.68 \pm 0.29$ & $0.69 \pm 0.24$ & $0.41 \pm 0.01$ & & $0.61 \pm 0.21$ & $0.65 \pm 0.25$ \\
\hline & $\AA$ & 1.74 & $1.55 \pm 0.12$ & $1.27 \pm 0.16$ & $1.09 \pm 0.07$ & & $0.4 \pm 0.10$ & $1.21 \pm 0.47$ \\
\hline & $\AA_{\mathrm{A}}$ & 1.25 & $1.32 \pm 0.21$ & $1.54 \pm 0.47$ & $1.43 \pm 0.72$ & & $2.28 \pm 0.29$ & $1.58 \pm 0.50$ \\
\hline & $R_{\mathrm{D}}$ & 0.08 & $0.21 \pm 0.04$ & $0.40 \pm 0.06$ & $0.54 \pm 0.03$ & & $0.85 \pm 0.06$ & $0.41 \pm 0.26$ \\
\hline & $\mathrm{CMF} \tau^{*}$ & 0.23 & $0.29 \pm 0.09$ & $0.47 \pm 0.16$ & $0.66 \pm 0.03$ & & $0.90 \pm 0.02$ & $0.49 \pm 0.26$ \\
\hline & $\mathrm{CMF}_{\mathrm{Vc}}$ & 0.24 & $0.36 \pm 0.07$ & $0.54 \pm 0.11$ & $0.65 \pm 0.01$ & & $0.88 \pm 0.02$ & $0.53 \pm 0.22$ \\
\hline & $\mathrm{CMF}_{\mathrm{vc}}-R_{\mathrm{D}}$ & 0.16 & 0.15 & 0.14 & 0.11 & & 0.04 & 0.12 \\
\hline \multirow{8}{*}{ Gosan } & No. & 18 & 47 & 47 & 19 & 5 & 3 & 139 \\
\hline & $\tau(500 \mathrm{~nm})$ & $0.6 \pm 0.24$ & $0.54 \pm 0.23$ & $0.54 \pm 0.17$ & $0.53 \pm 0.14$ & $0.41 \pm 0.02$ & $0.85 \pm 0.17$ & $0.55 \pm 0.20$ \\
\hline & $\AA$ & $1.55 \pm 0.14$ & $1.34 \pm 0.20$ & $1.27 \pm 0.18$ & $0.92 \pm 0.18$ & $0.77 \pm 0.11$ & $0.24 \pm 0.24$ & $0.124 \pm 0.30$ \\
\hline & $\AA_{\mathrm{A}}$ & $0.75 \pm 0.36$ & $0.91 \pm 0.48$ & $0.94 \pm 0.43$ & $0.95 \pm 0.59$ & $1.01 \pm 0.11$ & $2.39 \pm 0.70$ & $0.94 \pm 0.51$ \\
\hline & $R_{\mathrm{D}}$ & $0.08 \pm 0.02$ & $0.20 \pm 0.05$ & $0.37 \pm 0.04$ & $0.53 \pm 0.04$ & $0.71 \pm 0.02$ & $0.85 \pm 0.05$ & $0.32 \pm 0.18$ \\
\hline & $\mathrm{CMF} \tau^{*}$ & $0.24 \pm 0.07$ & $0.33 \pm 0.15$ & $0.53 \pm 0.11$ & $0.69 \pm 0.10$ & $0.81 \pm 0.02$ & $0.90 \pm 0.02$ & $0.47 \pm 0.21$ \\
\hline & $\mathrm{CMF}_{\mathrm{vc}}$ & $0.26 \pm 0.06$ & $0.37 \pm 0.10$ & $0.56 \pm 0.09$ & $0.68 \pm 0.08$ & $0.75 \pm 0.05$ & $0.89 \pm 0.08$ & $0.49 \pm 0.18$ \\
\hline & $\mathrm{CMF}_{\mathrm{vc}}-R_{\mathrm{D}}$ & 0.18 & 0.17 & 0.19 & 0.15 & 0.04 & 0.04 & 0.17 \\
\hline \multirow{8}{*}{ Osaka } & No. & 54 & 80 & 32 & 38 & 20 & 10 & 234 \\
\hline & $\tau(500 \mathrm{~nm})$ & $0.54 \pm 0.21$ & $0.47 \pm 0.18$ & $0.47 \pm 0.12$ & $0.54 \pm 0.15$ & $0.61 \pm 0.17$ & $0.58 \pm 0.15$ & $0.51 \pm 0.18$ \\
\hline & $\AA$ & $1.64 \pm 0.13$ & $1.52 \pm 0.16$ & $0.13 \pm 0.17$ & $1.01 \pm 0.14$ & $0.70 \pm 0.18$ & $0.26 \pm 0.08$ & $1.31 \pm 0.39$ \\
\hline & $\AA_{\mathrm{A}}$ & $1.18 \pm 0.25$ & $1.23 \pm 0.23$ & $1.37 \pm 0.43$ & $1.69 \pm 0.39$ & $1.57 \pm 0.43$ & $1.98 \pm 0.41$ & $1.37 \pm 0.39$ \\
\hline & $R_{\mathrm{D}}$ & $0.07 \pm 0.04$ & $0.20 \pm 0.06$ & $0.37 \pm 0.06$ & $0.55 \pm 0.05$ & $0.68 \pm 0.04$ & $0.86 \pm 0.04$ & $0.32 \pm 0.23$ \\
\hline & $\mathrm{CMF} \tau^{*}$ & $0.17 \pm 0.09$ & $0.30 \pm 0.12$ & $0.47 \pm 0.14$ & $0.69 \pm 0.07$ & $0.81 \pm 0.04$ & $0.91 \pm 0.01$ & $0.43 \pm 0.26$ \\
\hline & $\mathrm{CMF}_{\mathrm{vc}}$ & $0.21 \pm 0.06$ & $0.35 \pm 0.07$ & $0.52 \pm 0.08$ & $0.66 \pm 0.05$ & $0.79 \pm 0.06$ & $0.89 \pm 0.03$ & $0.45 \pm 0.22$ \\
\hline & $\mathrm{CMF}_{\mathrm{vc}}-R_{\mathrm{D}}$ & 0.14 & 0.15 & 0.15 & 0.11 & 0.11 & 0.03 & 0.13 \\
\hline
\end{tabular}

* $1020 \mathrm{~nm}$.

\subsection{Classification of AERONET-derived depolarization ratios based on values of $\delta_{\mathrm{P}}^{\mathrm{S}}$ at $1020 \mathrm{~nm}$}

The previous section showed that the depolarization ratio from AERONET does not agree with the lidar values at $532 \mathrm{~nm}$. A quantitative interpretation of the AERONET values is not possible. However, even if the quantitative numbers are wrong there may still be a possibility to use the AERONET numbers as qualitative indicators, i.e., trend. We must keep in mind, however, that the spectral slope of the depolarization ratios from AERONET are not correct for cases of (high) dust load.

We classified the observational data into six groups based on the values of $\delta_{\mathrm{P}}^{\mathrm{S}}$ at $1020 \mathrm{~nm}$. Group 1 contains cases for which the values of $\delta_{\mathrm{P}}^{\mathrm{S}}$ are 0.05 at $1020 \mathrm{~nm}$. Groups $2-5$ include values in the range of $0.05-0.1,0.1-0.15,0.15-0.2$, and $0.2-0.25$ at $1020 \mathrm{~nm}$, respectively. Values are above 0.25 in group 6.

Table 1 shows the number of data sets (observation cases) for each of the six data groups at the four observation sites. Table 1 also lists the averaged values of $\tau$ at $500 \mathrm{~nm}$, the optical-depth-related Ångström exponent ( $\AA$ ) between 440 and $870 \mathrm{~nm}$, and the light-absorption-related Ångström exponent $\left(\AA_{\mathrm{A}}\right)$ between 440 and $870 \mathrm{~nm}$ of each group. The values of $\tau$ are similar in all six groups. The reason for that similarity is because $\tau$ is insensitive to the shape and size of the particles. The values of $\AA_{A}$ increase. The values of $\AA$ decrease with increasing value of $\delta_{\mathrm{P}}^{\mathrm{S}}$. 

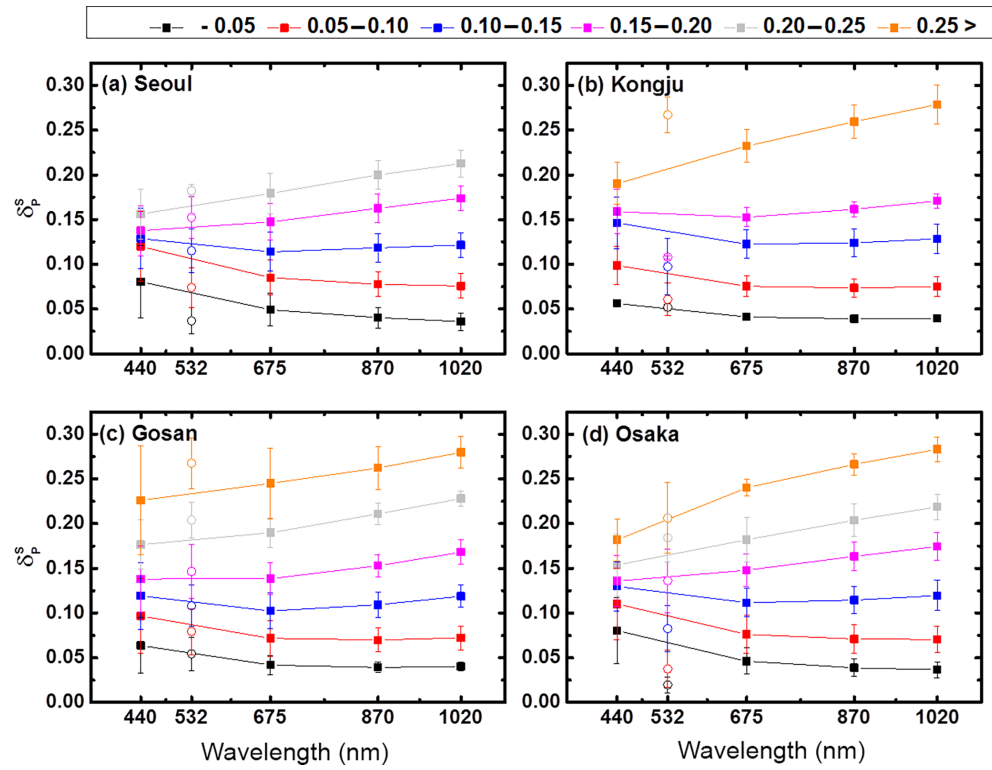

Figure 7. The average value of the $\delta_{\mathrm{P}}^{\mathrm{S}}$ at $440,675,870$, and $1020 \mathrm{~nm}$ for each group. Each group is distinguished by color: black (group 1), red (group 2), blue (group 3), pink (group 4), gray (group 5), and orange (group 6). The average values of the $\delta_{\mathrm{P}}^{\mathrm{CL}}$ at $532 \mathrm{~nm}$ are shown as open circles and the same color as the values of $\delta_{\mathrm{P}}^{\mathrm{S}}$.

Figure 7 shows the values $\delta_{\mathrm{P}}^{\mathrm{S}}$ of the six groups at the four measurement wavelengths of the AERONET sun-sky radiometers. There is a rather clear increase of $\delta_{\mathrm{P}}^{\mathrm{S}}$ with respect to increasing measurement wavelength in group 6 . We see a similar pattern in groups 4 and 5 , respectively. In contrast, groups 1-3 show the highest values of $\delta_{\mathrm{P}}^{\mathrm{S}}$ at $440 \mathrm{~nm}$ whereas the values of $\delta_{\mathrm{P}}^{\mathrm{S}}$ are similar at the other three measurement wavelengths.

Values of $\delta_{\mathrm{P}}^{\mathrm{L}}$ of pure mineral dust plumes were measured at three wavelengths $(355,532$, and $1064 \mathrm{~nm})$ with lidar (Freudenthaler et al., 2009) during SAMUM in 2006. Freudenthaler et al. (2009) found values of 0.31 for $\delta_{\mathrm{P}}^{\mathrm{L}}$ at $532 \mathrm{~nm}$. Müller et al. $(2010,2012)$ compared those data with data derived from collocated AERONET sun-sky radiometer observations. Values of $\delta_{\mathrm{p}}$ from both instruments agree at $1064 \mathrm{~nm}$ wavelength (Müller et al., 2010, 2012). If the sun-sky radiometer results are extrapolated to the lidar wavelength of $355 \mathrm{~nm}$, the value of $\delta_{\mathrm{p}}$ obtained from the sun-sky radiometer is $20 \%$ lower than the value obtained from the lidar observations (see Fig. 3 in Müller et al., 2010, and Fig. 7 in Müller et al., 2012).

Müller et al. (2010) find that the values of $\delta_{\mathrm{p}}$ inferred from the sun-sky radiometer observations tend to be lower than the values measured with lidar for the case of pure mineral dust. Only group 6 (Kongju and Gosan) shows 20-30\% lower values of $\delta_{\mathrm{P}}^{\mathrm{S}}$ compared to $\delta_{\mathrm{P}}^{\mathrm{CL}}$ in the visible wavelength range, which is a similar trend reported by Müller et al. (2010). This feature, i.e., that $\delta_{\mathrm{P}}^{\mathrm{CL}}$ is higher than $\delta_{\mathrm{P}}^{\mathrm{S}}$, is also found in group 5. However, the differences of the numbers are less compared to the differences we find for group 6 .
The opposite situation, i.e., $\delta_{\mathrm{P}}^{\mathrm{CL}}$ is lower than $\delta_{\mathrm{P}}^{\mathrm{S}}$, is found in groups 1-3. Figure 4 shows that the values of $\delta_{\mathrm{P}}^{\mathrm{S}}$ at $440 \mathrm{~nm}$ are significantly different from the values found at the other three wavelengths.

Figure 7 shows the values of $\delta_{\mathrm{P}}^{\mathrm{CL}}$ at $532 \mathrm{~nm}$ of each group. We find $0.27 \pm 0.02$ and $0.27 \pm 0.03$ at Kongju and Gosan, respectively, for group 6 . The values at the Osaka site are lower; we find $0.21 \pm 0.04$. The highest values of $\delta_{\mathrm{P}}^{\mathrm{CL}}$ are 0.29 at the Kongju and Gosan sites, respectively; see Fig. 4.

The differences of the $\delta_{\mathrm{p}}$ at the observation sites are likely caused by the appearance of dust. The transport distance to the four observation sites may have influence on the values of $\delta_{\mathrm{p}}$. Kongju and Gosan have similar transport distances from the source regions of East Asian dust. Osaka is located at a distance of 1 to 2 days of transport time from Kongju and Gosan. It means that more dust particles can be removed by gravity sedimentation during transport (Maring et al., 2003; Gong et al., 2003). Another reason may be that more anthropogenic pollution particles are mixed into these Asian dust plume because of the longer transport times (Kanayama et al., 2002; Noh et al., 2012a; Noh, 2014; Shin et al., 2015).

Figure 8 shows the averaged values of the vertically resolved $\beta_{\mathrm{P}}$, the values of $\delta_{\mathrm{P}}^{\mathrm{L}}$, and the weighted values of $\delta_{\mathrm{P}}^{\mathrm{L}}\left(\delta_{\mathrm{P}}^{\mathrm{LW}}\right)$ measured by lidar for each group. The backscatter coefficients generally decrease with height. However, high values are found in the upper atmosphere in those cases in which $\delta_{\mathrm{P}}^{\mathrm{L}}$ is high. Values of $\delta_{\mathrm{P}}^{\mathrm{L}}$ are as high as 0.1 in group 1 and increase with increasing group number (from group 1 to group 6). The increase of the values of $\delta_{\mathrm{P}}^{\mathrm{L}}$ is more obvi- 

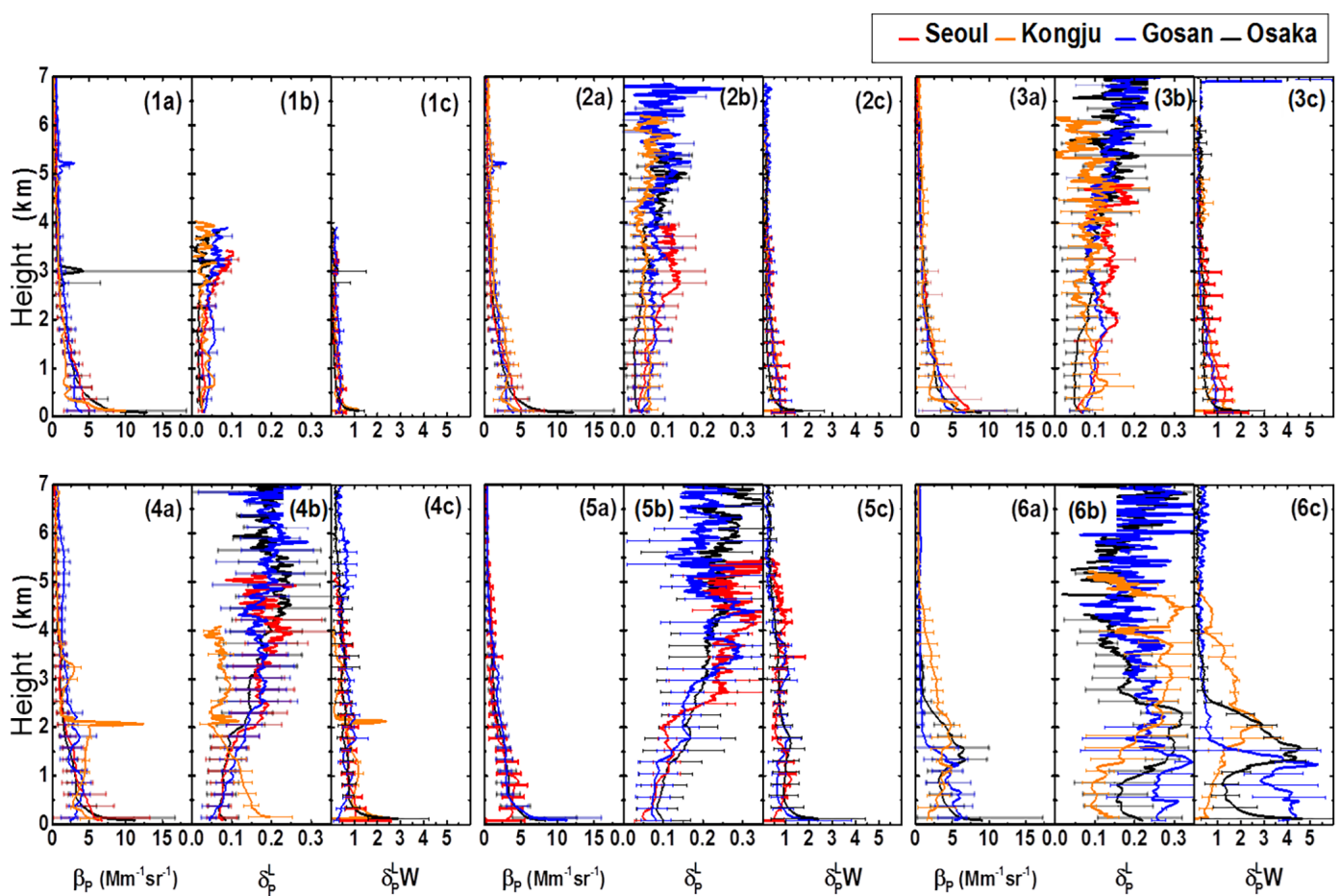

Figure 8. Average values of the vertical profiles of (a) the particle backscatter coefficient, (b) the linear particle depolarization ratios $\left(\delta_{\mathrm{P}}^{\mathrm{L}}\right)$, and (c) the weighted linear particle depolarization ratios $\left(\delta_{\mathrm{P}}^{\mathrm{LW}}\right)$ for group 1 (1), group 2 (2), group 3 (3), group 4 (4), group 5 (5), and group 6 (6). The sites are Seoul (red), Kongju (orange), Gosan (blue), and Osaka (black).

ous above $2 \mathrm{~km}$ height than below $2 \mathrm{~km}$ height above ground. The higher values above $2 \mathrm{~km}$ above ground may be caused by the fact that Asian dust has a relatively lower chance of being mixed with other pollutants if it is transported in the upper parts of the atmosphere (Shin et al., 2015). In particular, groups 5 and 6 show high values of $\delta_{\mathrm{P}}^{\mathrm{L}}$, i.e., larger than 0.3 above $2 \mathrm{~km}$ height.

We see that $\beta_{\mathrm{P}}$ shows different trends in these two groups. Group 5 has low values of $\beta_{\mathrm{P}}$ and high values of $\delta_{\mathrm{P}}^{\mathrm{L}}$. In contrast, group 6 shows high values of $\beta_{\mathrm{P}}$ and high values of $\delta_{\mathrm{P}}^{\mathrm{L}}$. This different behavior in these two groups is clearly visible in the values of $\delta_{\mathrm{P}}^{\mathrm{L}} W$. Values of $\delta_{\mathrm{P}}^{\mathrm{LW}}$ in group 5 are less than 2 throughout the whole altitude range. Values of $\delta_{\mathrm{P}}^{\mathrm{L}} W$ are larger than 2 in group 6.

Based on our discussion in the previous section we concluded that $\delta_{\mathrm{P}}^{\mathrm{S}}$ at $1020 \mathrm{~nm}$ may serve a qualitative indicator of the presence of mineral dust and that values of $\delta_{\mathrm{P}}^{\mathrm{S}}$ at $1020 \mathrm{~nm}$ are large for high dust concentrations and small for low dust concentrations (see Fig. 4, 7, and 8). This means that $\delta_{\mathrm{P}}^{\mathrm{S}}$ can be used to retrieve the dust ratio in mixed dust plumes even if vertically resolved information on the linear particle depolarization ratio is not available.

\subsection{Correlation between $\delta_{\mathrm{P}}^{\mathrm{S}}$ and SSA}

One main purpose of our study is to estimate the mixing ratio of dust particles with other pollutants in the atmosphere by analyzing the parameter $\delta_{\mathrm{P}}^{\mathrm{S}}$. Another purpose of our study is to use $\delta_{\mathrm{P}}^{\mathrm{S}}$ as the basis parameters for estimating the variation of the optical and microphysical properties of dust when it mixes with anthropogenic pollution particles. Correlations between $\delta_{\mathrm{P}}^{\mathrm{S}}$ and other optical parameters allow us to gain insight into these variations.

Variations of aerosol absorption properties can be described by the SSA. The variability of light absorption of aerosol mixtures discussed in this contribution allows us to assess the direct forcing of mixed dust plumes. We can also investigate the semi-direct forcing that may occur from atmospheric heating by absorbing aerosol layers (Noh et al., 2012b, 2016b; Noh, 2014). We also investigate how SSA varies with the volume particle size distribution. For these investigations we use the values of $\delta_{\mathrm{P}}^{\mathrm{S}}$.

Figure 9 depicts the AERONET-derived SSA and the volume particle size distributions for each of the six groups. The SSA spectra vary with changing $\delta_{\mathrm{P}}^{\mathrm{S}}$ in clearly distinguishable patterns. The SSA spectra of group 1 (low $\delta_{\mathrm{P}}^{\mathrm{S}}$ ) show that SSA decreases with increasing wavelength. We find that SSA decreases with increasing measurement wavelength for particle plumes that are dominated by urban-industrial and biomass burning particles (Dubovik et al., 2002; Giles et al., 2012). Black carbon particles have the strongest light-absorption capacity in the near-infrared wavelength region.

In contrast, the SSA spectra of group 6 (high $\delta_{\mathrm{P}}^{\mathrm{S}}$ ) show an increase of SSA with increasing wavelength. The wave- 


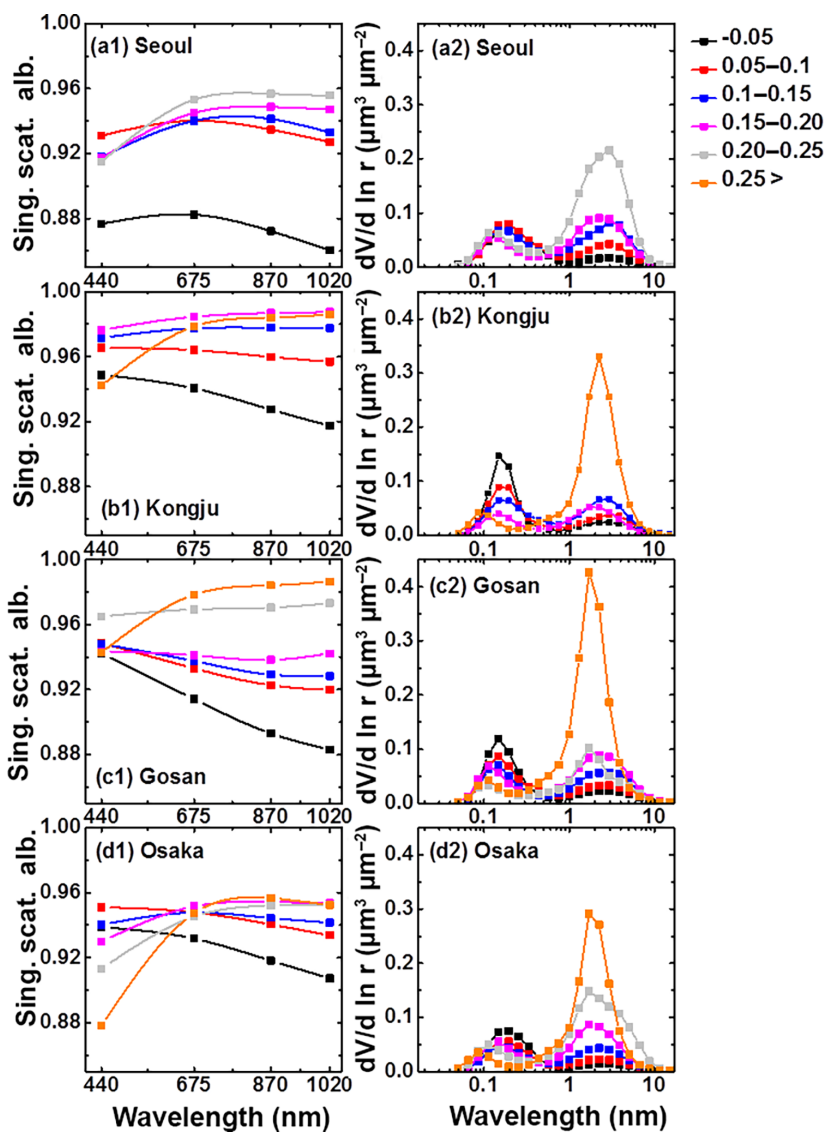

Figure 9. Average value of the SSA and the volume particle size distributions derived from the AERONET sun-sky radiometer measurements for each of the six groups considered in this study: group 1 (black), group 2 (red), group 3 (blue), group 4 (pink), group 5 (gray), and group 6 (orange).

length dependence (i.e., increasing, decreasing, or constant with wavelength) of SSA is an important property that is used in aerosol type classification because the spectral absorption characteristics depend on aerosol type (Giles et al., 2012; Russell et al., 2010; Eck et al., 2005, 2010; Dubovik et al., 2002).

The increase of SSA with increasing wavelength is a characteristic optical feature of desert dust particles (Giles et al., 2012). Dust exhibits strong light absorption in the ultraviolet (UV) and at short visible wavelengths (e.g., $440 \mathrm{~nm}$ ) and lower light absorption from mid-visible to near-infrared wavelengths (Sokolik and Toon, 1999).

Kim et al. (2011) define particles with $\AA<0.2$ as "pure dust" based on observations of dust particles over North Africa and the Arabian Peninsula. The average value of SSA of the "pure dust" part of the aerosol plumes observed at the four observation sites is $0.91,0.97,0.97$, and 0.97 at 440 , 675,870 , and $1020 \mathrm{~nm}$ wavelength, respectively.

The SSA spectra of group 6 at Kongju, Gosan, and Osaka resemble the SSA spectra of "pure dust" described by Kim et al. (2011). The SSAs of group 6 at Kongju and Gosan show similar values reported by Kim et al. (2011), i.e., 0.94, 0.98, 0.98 , and 0.99 at $440,675,870$, and $1020 \mathrm{~nm}$ wavelength, respectively. Lower values of SSA are observed at Osaka; we find $0.88,0.95,0.96$, and 0.95 at $440,675,870$, and $1020 \mathrm{~nm}$ wavelength, respectively. The differences of SSA at Osaka may be caused by the mixing of pollution particles with dust.

Except for the SSA at $440 \mathrm{~nm}$, the SSAs at 675, 870, and $1020 \mathrm{~nm}$ show higher values for high $\delta_{\mathrm{P}}^{\mathrm{S}}$. This increase of SSA with increasing $\delta_{\mathrm{P}}^{\mathrm{S}}$ results from the mixing of fine-mode pollution particles with coarse-mode Asian dust.

Mixtures of desert dust and pollution aerosols contain two primary particulate light-absorbing species: black carbon in fine-mode particles (Bond and Bergstrom, 2006) and iron oxides in coarse-mode dust particles (Sokolik and Toon, 1999). Iron oxides cause strong light absorption in the UV and in the short-wavelength range of the visible spectral range of light (Derimian et al., 2008). In pollution particles the principal absorber is soot or black carbon, which exhibits light absorption throughout the entire solar spectrum, because the imaginary part of the complex refractive index shows comparably little wavelength dependence (Bergstrom et al., 2002).

The SSA as a function of $\delta_{\mathrm{P}}^{\mathrm{S}}$ at the Seoul and Gosan sites shows very little variation at $440 \mathrm{~nm}$ compared to the other wavelengths we considered in our study $(675,870$, and $1020 \mathrm{~nm}$ ). Eck et al. (2010) suggest that this low variation of SSA at $440 \mathrm{~nm}$ is induced when both coarse-modedominated aerosol mixtures (desert dust) and fine-modedominated aerosol mixtures (pollution) have relatively similar magnitudes of light absorption compared to their lightscattering capacity at that wavelength.

The variations of the fine-mode and the coarse-mode parts of the size distributions are clearly shown in Fig. 9. Group 1 contains fine-mode-dominated particle size distributions. The fine-mode part of the particle size distributions decreases and the coarse-mode part of the size distributions increases for increasing $\delta_{\mathrm{P}}^{\mathrm{S}}$. The variations of $\mathrm{Cv}_{\mathrm{c}} / \mathrm{Cv}_{\mathrm{f}}$ for each group listed in Table 2 show these tendencies more clearly.

The values of $\mathrm{Cv}_{\mathrm{c}} / \mathrm{Cv}_{\mathrm{f}}$ increase as we move from group 1 to 6. The values of $\mathrm{Cv}_{\mathrm{c}} / \mathrm{Cv}_{\mathrm{f}}$ in group 1 are similar at Seoul, Kongju, Gosan, and Osaka; we find 0.29, 0.32, 0.35, and 0.28 , respectively. The values of $\mathrm{Cv}_{\mathrm{c}} / \mathrm{Cv}_{\mathrm{f}}$ are similar for all three observation sites for each of the groups 1-5.

However, in the case of group $6, \mathrm{Cv}_{\mathrm{c}} / \mathrm{Cv}_{\mathrm{f}}$ is $7.6,11.3$, and 8.6 at Kongju, Gosan, and Osaka, respectively. The values of $\mathrm{Cv}_{\mathrm{c}} / \mathrm{Cv}_{\mathrm{f}}$ in group 6 are smaller than the average value at Dunhuang. The average value of $\mathrm{Cv}_{\mathrm{c}} / \mathrm{Cv}_{\mathrm{f}}$ at Dunhuang is $15.0 \pm 2.6$ (see Table 4). $\mathrm{Cv}_{\mathrm{c}} / \mathrm{Cv}_{\mathrm{f}}$ decreases if finemode pollution particles are mixed into a dust plume and/or if coarse-mode dust particles are removed from the plume during long-range transport. 
Table 2. Averaged volume concentration of the fine $\left(\mathrm{Cv}_{\mathrm{f}}\right)$ and the coarse $\left(\mathrm{Cv}_{\mathrm{c}}\right)$ modes and the ratio $\left(\mathrm{Cv}_{\mathrm{c}} / \mathrm{Cv}_{\mathrm{f}}\right)$ for the six groups.

\begin{tabular}{|c|c|c|c|c|c|c|c|c|}
\hline & & $\begin{array}{r}\text { Group } 1 \\
0-0.05\end{array}$ & $\begin{array}{r}\text { Group } 2 \\
0.05-0.1\end{array}$ & $\begin{array}{l}\text { Group } 3 \\
0.1-0.15\end{array}$ & $\begin{array}{r}\text { Group } 4 \\
0.15-0.2\end{array}$ & $\begin{array}{l}\text { Group } 5 \\
0.2-0.25\end{array}$ & $\begin{array}{c}\text { Group } 6 \\
0.25>\end{array}$ & Total \\
\hline Seoul & $\begin{array}{l}\mathrm{Cv}_{\mathrm{f}} \\
\mathrm{Cv}_{\mathrm{c}} \\
\mathrm{Cv}_{\mathrm{c}} / \mathrm{Cv}_{\mathrm{f}}\end{array}$ & $\begin{array}{r}0.112 \pm 0.051 \\
0.031 \pm 0.013 \\
0.29 \pm 0.10\end{array}$ & $\begin{array}{r}0.117 \pm 0.052 \\
0.069 \pm 0.032 \\
0.66 \pm 0.29\end{array}$ & $\begin{array}{r}0.103 \pm 0.042 \\
0.132 \pm 0.052 \\
1.39 \pm 0.54\end{array}$ & $\begin{array}{r}0.067 \pm 0.032 \\
0.162 \pm 0.071 \\
2.45 \pm 0.65\end{array}$ & $\begin{array}{r}0.082 \pm 0.021 \\
0.352 \pm 0.172 \\
4.26 \pm 1.60\end{array}$ & & $\begin{array}{r}0.11 \pm 0.05 \\
0.098 \pm 0.081 \\
1.11 \pm 0.99\end{array}$ \\
\hline Kongju & $\begin{array}{l}\mathrm{Cv}_{\mathrm{f}} \\
\mathrm{Cv}_{\mathrm{c}} \\
\mathrm{Cv}_{\mathrm{c}} / \mathrm{Cv}_{\mathrm{f}}\end{array}$ & $\begin{array}{r}0.136 \\
0.044 \\
0.32\end{array}$ & $\begin{array}{r}0.109 \pm 0.044 \\
0.062 \pm 0.027 \\
0.59 \pm 0.19\end{array}$ & $\begin{array}{r}0.092 \pm 0.038 \\
0.105 \pm 0.029 \\
1.29 \pm 0.63\end{array}$ & $\begin{array}{r}0.046 \pm 0.004 \\
0.085 \pm 0.012 \\
1.84 \pm 0.12\end{array}$ & & $\begin{array}{r}0.048 \pm 0.018 \\
0.361 \pm 0.148 \\
7.61 \pm 1.44\end{array}$ & $\begin{array}{r}0.088 \pm 0.044 \\
0.138 \pm 0 . .140 \\
2.37 \pm 2.95\end{array}$ \\
\hline Gosan & $\begin{array}{l}\mathrm{Cv}_{\mathrm{f}} \\
\mathrm{Cv}_{\mathrm{c}} \\
\mathrm{Cv}_{\mathrm{c}} / \mathrm{Cv}_{\mathrm{f}}\end{array}$ & $\begin{array}{r}0.127 \pm 0.043 \\
0.043 \pm 0.016 \\
0.35 \pm 0.12\end{array}$ & $\begin{array}{r}0.104 \pm 0.044 \\
0.059 \pm 0.027 \\
0.63 \pm 0.31\end{array}$ & $\begin{array}{r}0.081 \pm 0.036 \\
0.105 \pm 0.042 \\
1.40 \pm 0.57\end{array}$ & $\begin{array}{r}0.074 \pm 0.038 \\
0.159 \pm 0.068 \\
2.36 \pm 0.89\end{array}$ & $\begin{array}{r}0.042 \pm 0.002 \\
0.136 \pm 0.059 \\
3.18 \pm 1.21\end{array}$ & $\begin{array}{r}0.054 \pm 0.039 \\
0.444 \pm 0.125 \\
11.26 \pm 7.07\end{array}$ & $\begin{array}{r}0.091 \pm 0.043 \\
0.098 \pm 0.077 \\
1.41 \pm 1.92\end{array}$ \\
\hline Osaka & $\begin{array}{l}\mathrm{Cv}_{\mathrm{f}} \\
\mathrm{Cv}_{\mathrm{c}} \\
\mathrm{Cv}_{\mathrm{c}} / \mathrm{Cv}_{\mathrm{f}}\end{array}$ & $\begin{array}{r}0.103 \pm 0.037 \\
0.027 \pm 0.011 \\
0.28 \pm 0.11\end{array}$ & $\begin{array}{r}0.077 \pm 0.030 \\
0.040 \pm 0.015 \\
0.56 \pm 0.18\end{array}$ & $\begin{array}{r}0.065 \pm 0.019 \\
0.072 \pm 0.028 \\
1.13 \pm 0.35\end{array}$ & $\begin{array}{r}0.066 \pm 0.018 \\
0.135 \pm 0.047 \\
2.04 \pm 0.43\end{array}$ & $\begin{array}{r}0.059 \pm 0.016 \\
0.253 \pm 0.147 \\
4.49 \pm 2.58\end{array}$ & $\begin{array}{r}0.039 \pm 0.008 \\
0.326 \pm 0.094 \\
8.49 \pm 2.55\end{array}$ & $\begin{array}{r}0.076 \pm 0.031 \\
0.087 \pm 0.097 \\
1.49 \pm 2.10\end{array}$ \\
\hline
\end{tabular}
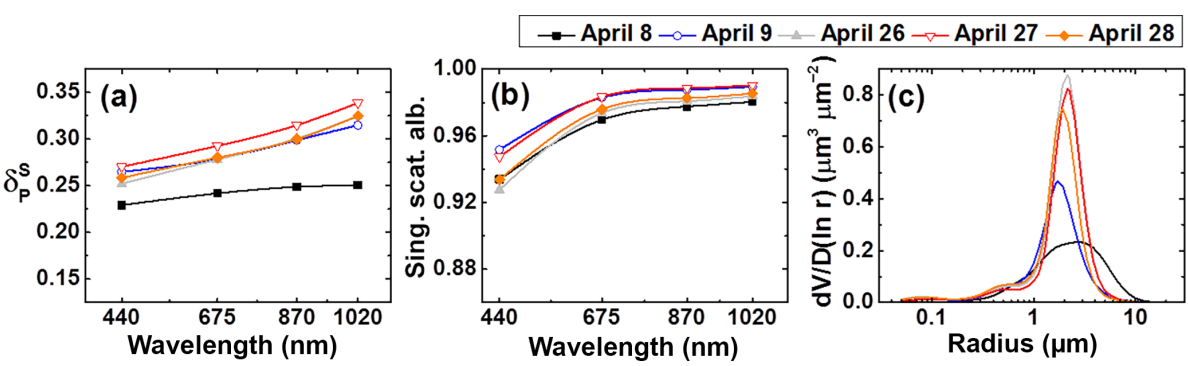

Figure 10. (a) Linear particle depolarization ratios, (b) single-scattering albedos, and (c) volume particle size distributions derived from sun-sky radiometer observations at Dunhuang.

\section{4 $\delta_{\mathbf{P}}^{\mathrm{S}}, \mathrm{SSA}$, and particle size distribution at the dust source region}

We analyzed the AERONET sun-sky radiometer data taken in the source region of Asian dust and evaluated the optical properties and $\delta_{\mathrm{P}}^{\mathrm{S}}$ of "pure Asian dust". Figure 10 shows $\delta_{\mathrm{P}}^{\mathrm{S}}$, SSA, and volume particle size distributions observed on 5 days in one of the source regions of Asian dust, i.e., Dunhuang in 2012. Values of $\delta_{\mathrm{P}}^{\mathrm{S}}$ at $440 \mathrm{~nm}$ are characteristic of pure dust particles; i.e., we find values larger than 0.25. SSA increases with increasing measurement wavelength, which is also characteristic of pure dust. We find this behavior on all days except for the data representing 8 April 2012. We find that the SSA at each wavelength (at the Dunhuang site) is higher than the SSA retrieved at the corresponding wavelengths for sites in North Africa and the Arabian Peninsula (Kim et al., 2011; Müller et al., 2010).

Table 3 lists aerosol optical depth $(\tau)$ at $500 \mathrm{~nm}$, the optical-depth-related $\AA$ for the wavelength range from 440 to $870 \mathrm{~nm}$, the absorption-related $\AA_{\mathrm{A}}$ for that same wavelength range, the coarse-mode fraction of the volume concentration $\left(\mathrm{CMF}_{\mathrm{vc}}\right)$, and the dust ratio $\left(R_{\mathrm{D}}\right)$ derived on the basis of $\delta_{\mathrm{P}}^{\mathrm{S}}$ at $1020 \mathrm{~nm}$. The values of $\AA$ observed at Dunhuang on all measurement dates used in this study indicate the presence of pure dust, as suggested by Kim et al. (2011). The exception is the measurement on 8 April 2012. On that day, we find a value of 0.25 for $\delta_{\mathrm{P}}^{\mathrm{S}}$ at $1020 \mathrm{~nm}$ and a value of 1.76 for $\AA_{A}$. These values are comparably lower than the values retrieved for the other observation days. In addition, volume particle size distributions retrieved for 8 April (see Fig. 10) show a higher value of the modal volume radius for the coarse-mode size distribution compared to what is typically found for size distributions of desert dust (Dubovik et al., 2002; Müller et al., 2010, 2012). We conclude that particles observed on 8 April 2012 describe a mixed dust plume rather than a pure dust plume.

We compare the average values of $\delta_{\mathrm{P}}^{\mathrm{S}}$, SSA, and the volume particle size distributions observed at Dunhuang with the respective values of group 6 at Kongju, Gosan, and Osaka. We exclude the data taken on 8 April 2012 at Dunhuang in the calculation of the average values because those data likely do not represent pure Asian dust.

Figure 11 shows our comparison results. The highest values of $\delta_{\mathrm{P}}^{\mathrm{S}}$ at Dunhuang are $0.26,0.28,0.30$, and 0.33 at 440 , 675,870 , and $1020 \mathrm{~nm}$ wavelength, respectively. The spectral behavior of $\delta_{\mathrm{P}}^{\mathrm{S}}$ (at the four wavelengths) at Kongju, Gosan, and Osaka is similar to the spectral behavior of $\delta_{\mathrm{P}}^{\mathrm{S}}$ retrieved for the Dunhuang site. However, the values of $\delta_{\mathrm{P}}^{\mathrm{S}}$ at the 
Table 3. Aerosol optical depth $(\tau)$ at $500 \mathrm{~nm}$, linear particle depolarization ratio $\left(\delta_{\mathrm{P}}^{\mathrm{S}}\right)$ derived from the sun-sky radiometer data, optical-depthrelated Ångström exponent ( $\AA$, 440-870 nm), absorption-related Ångström exponent $\left(\AA_{\mathrm{A}}\right)$, coarse-mode fraction in terms of the volume concentration $\left(\mathrm{CMF}_{\mathrm{vc}}\right)$, and dust ratio $\left(R_{\mathrm{D}}\right)$ at $1020 \mathrm{~nm}$. The observation site is Dunhuang.

\begin{tabular}{lcccccc}
\hline Date & $\begin{array}{c}\tau \\
(500 \mathrm{~nm})\end{array}$ & $\begin{array}{c}\delta_{\mathrm{P}}^{\mathrm{S}} \\
(1020 \mathrm{~nm})\end{array}$ & $\begin{array}{c}\AA \\
(440-870 \mathrm{~nm})\end{array}$ & $\AA_{\mathrm{A}}$ & $\mathrm{CMF}_{\mathrm{vc}}$ & $R_{\mathrm{D}}$ \\
\hline $8 \mathrm{Apr}$ & 0.71 & 0.25 & 0.13 & 1.76 & 0.94 & 0.77 \\
$9 \mathrm{Apr}$ & 0.92 & 0.31 & 0.12 & 2.17 & 0.93 & 0.94 \\
$26 \mathrm{Apr}$ & 1.17 & 0.32 & 0.14 & 2.14 & 0.94 & 0.96 \\
$27 \mathrm{Apr}$ & 1.00 & 0.34 & 0.15 & 2.46 & 0.95 & 0.99 \\
$28 \mathrm{Apr}$. & 1.16 & 0.32 & 0.17 & 2.19 & 0.93 & 0.96 \\
\hline Ave. $^{1}$ & $0.97 \pm 0.17$ & $0.31 \pm 0.03$ & $0.14 \pm 0.02$ & $2.14 \pm 0.25$ & $0.94 \pm 0.01$ & $0.93 \pm 0.09$ \\
\hline Ave. $^{2}$ & $1.04 \pm 0.11$ & $0.33 \pm 0.01$ & $0.14 \pm 0.02$ & $2.24 \pm 0.15$ & $0.94 \pm 0.01$ & $0.97 \pm 0.02$ \\
\hline
\end{tabular}

${ }^{1}$ Averaged for all data; ${ }^{2}$ averaged except 8 April data.

Table 4. Volume concentration of the fine $\left(\mathrm{Cv}_{f}\right)$ and the coarse $\left(\mathrm{Cv}_{\mathrm{c}}\right)$ modes and the ratio $\left(\mathrm{Cv}_{\mathrm{c}} / \mathrm{Cv}_{\mathrm{f}}\right)$ at Dunhuang.

\begin{tabular}{lrrrrrrr}
\hline Date & $8 \mathrm{Apr}$ & $9 \mathrm{Apr}$ & $26 \mathrm{Apr}$ & $27 \mathrm{Apr}$ & $28 \mathrm{Apr}$ & Ave. $^{1}$ & Ave. $^{2}$ \\
\hline $\mathrm{Cv}_{\mathrm{f}}$ & 0.03 & 0.037 & 0.048 & 0.038 & 0.051 & $0.041 \pm 0.01$ & $0.044 \pm 0.01$ \\
$\mathrm{Cv}_{\mathrm{c}}$ & 0.44 & 0.49 & 0.77 & 0.7 & 0.64 & $0.61 \pm 0.14$ & $0.65 \pm 0.12$ \\
$\mathrm{Cv}_{\mathrm{c}} / \mathrm{Cv}_{\mathrm{f}}$ & 14.8 & 13.2 & 16 & 18.3 & 12.6 & $14.9 \pm 2.3$ & $15.0 \pm 2.6$ \\
\hline
\end{tabular}

${ }^{1}$ Averaged for all data; ${ }^{2}$ averaged except 8 April data.
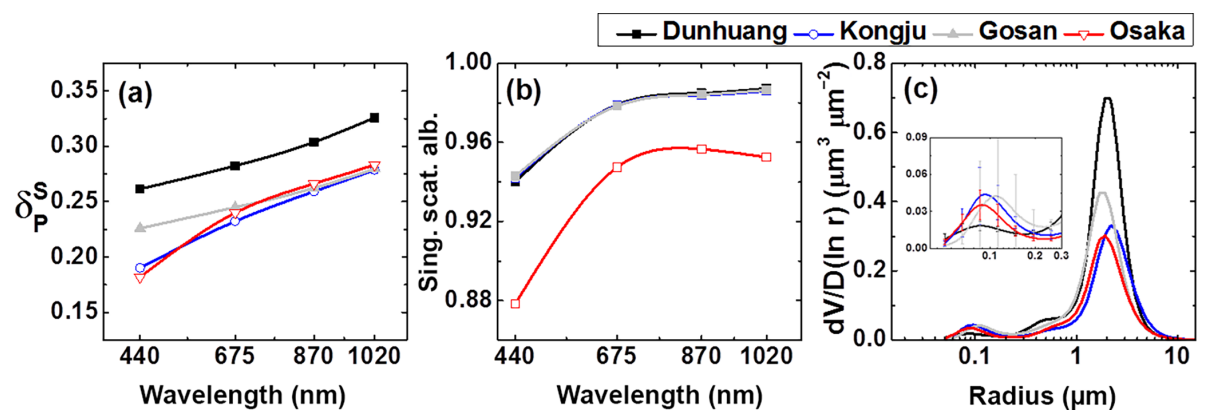

Figure 11. Comparison between (a) $\delta_{\mathrm{P}}^{\mathrm{S}}$, (b) SSA, and volume particle size distributions representing the dust source region (Dunhuang, black) and group 6 data (Kongju, blue; Gosan, gray; Osaka, red).

four measurement wavelengths at Kongju, Gosan, and Osaka are 0.04-0.05 lower than the respective values at the Dunhuang site. This difference between Dunhuang and the other three sites may be caused by gravitational settling of coarsemode dust particles during transport and/or by a higher share of anthropogenic pollution particles that may enter the dust plume during long-range transport from the source region to the other three sites.

The volume particle size distributions shown in Fig. 11c corroborate our assumption. The volume concentration of the coarse-mode particles is as low as $0.36,0.44$, and 0.33 $\left(\mu \mathrm{m}^{3} \mu \mathrm{m}^{-2}\right)$ in the far-field sites of Kongju, Gosan, and Osaka, respectively. We find that among all days during which we observed pure Asian dust at Dunhuang, the minimum value of $0.49\left(\mu \mathrm{m}^{3} \mu \mathrm{m}^{-2}\right)$ was found on 9 April 2012 (see Fig. 11c and Table 4).

Figure $11 \mathrm{~b}$ shows a comparison of the spectral SSA between Dunhuang and the other three sites. The average values of SSA at Dunhuang are 0.94, 0.98, 0.98, and 0.98 at 440, 675,870 , and $1020 \mathrm{~nm}$, respectively. The value of 0.94 for SSA at $440 \mathrm{~nm}$ at the Dunhuang site is higher than the SSA of "pure dust" observed over North Africa and the Arabian Peninsula (Kim et al., 2011; Müller et al., 2010, 2011).

As noticed previously, iron oxides cause the strongest light absorption in the ultraviolet and at visible wavelengths (Derimian et al., 2008). We assume that the differences of SSA at $440 \mathrm{~nm}$ between the Dunhuang site and observation sites in North Africa and the Arabian Peninsula are caused by dif- 
ferences of the chemical composition of dust particles, as for example by the concentration of iron oxides in dust particles at these sites.

Our results show that nearly pure dust may be transported to Kongju and Gosan from long distances and that the CMF of the particle size distribution may not necessarily increase in that case. The spectral behavior of SSA and its values at each wavelength at the Kongju and Gosan sites, which are long-range transport sites, match the values of SSA at Dunhuang. This match suggests that the dust at these three sites may have a similar chemical composition and perhaps also a similar concentration of iron oxide.

SSA values at Osaka are lower than those at Kongju and Gosan. We find values of $0.88,0.95,0.96$, and 0.95 at 440 , 675,870 , and $1020 \mathrm{~nm}$, respectively. These low SSAs can be caused by the presence of pollution particles. We first investigate the vertical distribution of the dust plumes of group 6 at Osaka. The vertical distribution of particles in the dust plumes of group 6 at Osaka can be clearly distinguished according to their observation date.

Figure 12 shows the separated values of $\beta_{\mathrm{P}}, \delta_{\mathrm{P}}^{\mathrm{L}}$, and $\delta_{\mathrm{P}}^{\mathrm{LW}}$ (dust and non-dust contribution) in terms of cases 1 and 2 for group 6 at Osaka on the basis of the observation date. The data taken on 14 and 15 March 2010 (case 1) show that the dust plumes are distributed up to $3.5 \mathrm{~km}$ above the ground. The main part of the dust plumes is located between 1 and $2 \mathrm{~km}$ height on both days. The values of $\delta_{\mathrm{P}}^{\mathrm{L}}$ are above 0.25 in that height range. The $\beta_{\mathrm{P}}$ values of the dust plume are lower below $1 \mathrm{~km}$ height compared to what we find for $\beta$ above $1 \mathrm{~km}$ above ground. The value of $\delta_{\mathrm{P}}^{\mathrm{L}}$ varies between 0.1 and 0.12 and thus is lower than what we find between 1 and $2 \mathrm{~km}$ height.

The dust plumes extend to $2 \mathrm{~km}$ height above ground on 2 May 2011 (measurement case 2). We find high values of $\beta_{\mathrm{P}}$ near the surface. Values of $0.3-0.4$ for $\delta_{\mathrm{P}}^{\mathrm{L}}$ are higher than depolarization ratios found for case 1 .

Case 1 is quite different from case 2 if we look at $\delta_{\mathrm{P}}^{\mathrm{LW}}$. The values of $\delta_{\mathrm{P}}^{\mathrm{LW}}$ of case 1 are mainly affected by Asian dust that is present above $1 \mathrm{~km}$ height above ground. Values for case 2 are mainly influenced by Asian dust near the surface.

The differences of main aerosol height may be one reason why the light-absorption capacity of the aerosols described by these two cases differs. With regard to case 2 , there is a higher possibility that pollutants can be mixed during longrange transport.

Figure 13 corroborates our assumption. Figure 13 shows values of $\delta_{\mathrm{P}}^{\mathrm{S}}$, SSA, and volume particle size distributions for two cases. The values of $\delta_{\mathrm{P}}^{\mathrm{S}}$ and SSA in case 1 show similar values compared to the case of pure dust observed at Dunhuang. Values of these parameters are different from those at Dunhuang for case 2. Particularly, the values of SSA of case 2 are significantly lower than SSA values at Dunhuang. Moreover, SSAs at $1020 \mathrm{~nm}$ are lower than those at $870 \mathrm{~nm}$ for case 2. This differences of the absolute values and the differences of the spectral behavior may be caused by the

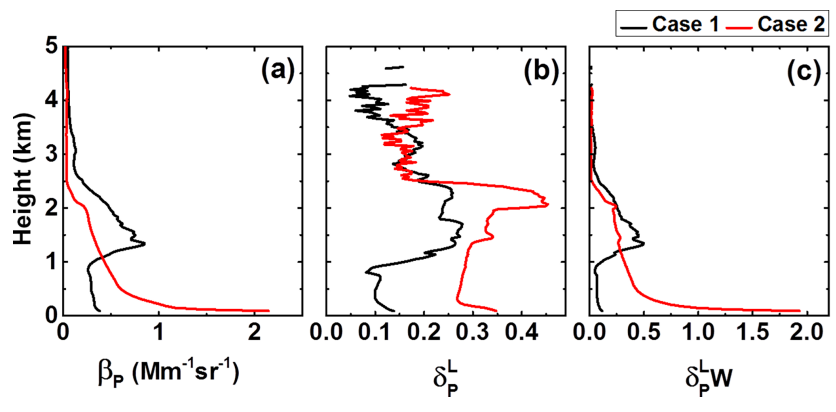

Figure 12. Separation of data of group 6 at Osaka on the basis of case 1 (black) and case 2 (red). Shown are (a) backscatter coefficients, (b) linear particle depolarization ratios $\left(\delta_{\mathrm{P}}^{\mathrm{L}}\right)$, and (c) weighted linear particle depolarization $\operatorname{ratios}\left(\delta_{\mathrm{P}}^{\mathrm{LW}}\right)$.

mixing of dust with light-absorbing pollutants, such as black carbon, when we take account of the vertical distribution of the dust plume (see Fig. 12).

The differences of $\AA_{\mathrm{A}}$ between case 1 and case 2 (Table 5) corroborate this observation. The value of $\AA_{A}$ in case 1 is 2.12 , which points to pure dust. In contrast, the value of $\AA_{\mathrm{A}}$ of case 2 is 1.58 , which is more likely representative of a mixture of dust with pollutants (Russell et al., 2010).

Figure 14 shows backward trajectories. The transport pattern is different for case 1 and case 2 . The main portions of the dust plumes of case 1 passed at heights above $1.5-2 \mathrm{~km}$ over source regions of major pollution emissions in China and the Korean Peninsula, i.e., above the PBL, before the plumes arrived over Osaka. Since most of the pollution resides in the PBL the possibility is low that the main dust layer mixed with pollutants.

In contrast to case 1 , case 2 indicates that pollutants were mixed into the Asian dust layers while they were transported near the surface and within the PBL over industrialized areas and before they arrived over Osaka. Shin et al. (2015) reported that more pollution particles can be mixed into dust plumes if these plumes are transported at low altitude above ground.

\subsection{Retrieval of dust ratio using depolarization ratio derived by sun-sky radiometer}

The concept of separating lidar backscatter signals resulting from the contribution of dust particles in mixed dust plumes to the total backscatter signals using $\delta_{\mathrm{p}}$ has already been applied to lidar measurements (Shimizu et al., 2004; Noh, 2014; Tesche et al., 2009). In the case of AERONET sun-sky radiometer data $R_{\mathrm{D}}$ is calculated from Eq. (2) (see Sect. 2) and the use of $\delta_{\mathrm{P}}^{\mathrm{S}}$ at $1020 \mathrm{~nm}$. The retrieved $R_{\mathrm{D}}$ is compared with $\mathrm{CMF}_{\mathrm{vc}}$. The comparison between $R_{\mathrm{D}}$ retrieved from AERONET data and $\mathrm{CMF}_{\mathrm{vc}}$ allows us to distinguish between non-dust coarse-mode particles and dust.

Figure 15 shows the correlation between $R_{\mathrm{D}}$ and $\mathrm{CMF}_{\mathrm{vc}}$ in terms of $R^{2}$. We find a comparably high correlation be- 

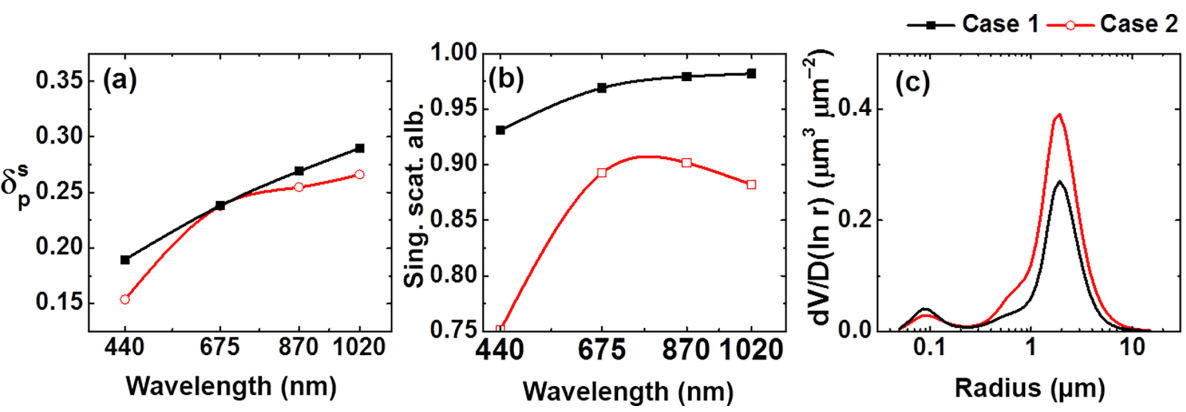

Figure 13. (a) $\delta_{\mathrm{P}}^{\mathrm{S}}$ at 440, 675, 870, and $1020 \mathrm{~nm}$; (b) SSA at 440, 675, 870, and $1020 \mathrm{~nm}$; and (c) volume particle size distributions. Shown are the results for case 1 (black) and case 2 (red). $\mathrm{Cv}_{\mathrm{c}} / \mathrm{Cv}_{\mathrm{f}}$ is inserted in (c). The observation site is Osaka.

(a) Case 1

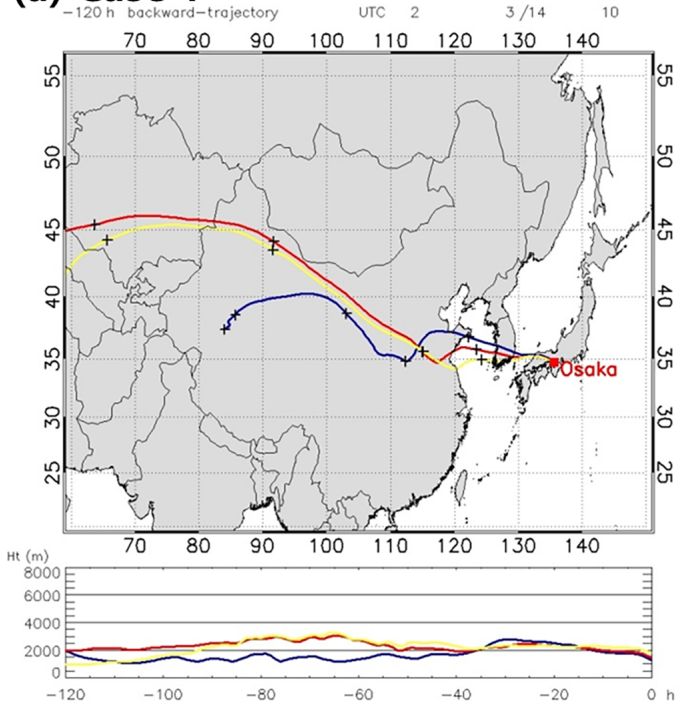

(b) Case 2

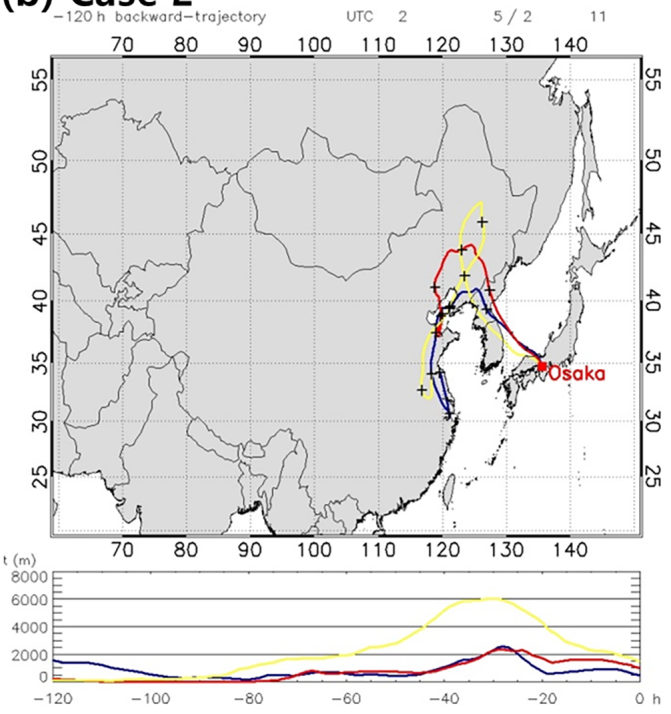

Figure 14. HYSPLIT 5-day backward trajectories of dust plumes for case 1 (a) and case 2 (b). The start heights for case 1 are $1200 \mathrm{~m}$ (blue), $1500 \mathrm{~m}$ (red), and $1800 \mathrm{~m}$ (yellow). For case 2 they are $500 \mathrm{~m}$ (blue), $1000 \mathrm{~m}$ (red), and $1500 \mathrm{~m}$ (yellow). The start time is 00:00 UTC in each case.

tween $R_{\mathrm{D}}$ and $\mathrm{CMF}_{\mathrm{vc}}$. Values are $0.72,0.95,0.77$, and 0.93 at Seoul, Kongju, Gosan, and Osaka, respectively.

$R_{\mathrm{D}}$ describes the ratio of dust particles to other types of non-spherical aerosols in the atmosphere. Unlike $R_{\mathrm{D}}, \mathrm{CMF}_{\mathrm{vc}}$ considers the size of particles and is not correlated to the shape of the particles. Since most of the dust particles belong to the $\mathrm{CMF}$, the value of $\mathrm{CMF}_{\mathrm{vc}}$ increases with the dust ratio. However, the coarse mode of a particle size distribution includes not only dust but also large particles that are generated by physical and chemical reactions, e.g., coagulation, condensation processes, and hygroscopic growth.

Figure 15 shows that $\mathrm{CMF}_{\mathrm{vc}}$ is on average $0.12-0.17$ higher than $R_{\mathrm{D}}$ at the four observation sites, which implies that non-dust particles are present; i.e., even though dust particles for the most part belong to the CMF of particle size distributions, not all coarse-mode particles are dust particles. The average values of $\mathrm{CMF}_{\mathrm{vc}}$ and the differences between
$R_{\mathrm{D}}$ and $\mathrm{CMF}_{\mathrm{vc}}$ for each of the six groups are listed in $\mathrm{Ta}-$ ble 1 .

$R_{\mathrm{D}}$ of groups $1-5$ is $0.11-0.19$ lower than $\mathrm{CMF}_{\mathrm{vc}}$ at the four sites. The differences between $R_{\mathrm{D}}$ and $\mathrm{CMF}_{\mathrm{vc}}$ are lower for group 6. We find 0.4, 0.4, and 0.3 at Kongju, Gosan, and Osaka, respectively.

We find a similar difference for the Dunhuang site (see Table 3). The average values of $R_{\mathrm{D}}$ and $\mathrm{CMF}_{\mathrm{vc}}$ are $0.97 \pm 0.02$ and $0.94 \pm 0.01$, respectively, except for the case of 8 April. This means that most of the coarse-mode particles are composed of dust particles. However, pollution and/or biomass burning particles can be injected into the dust plume during transport from the source region. These particles may contribute to the coarse mode of the volume particle size distribution. If the dust plume is transported at low altitude above ground, there is an increased possibility that dust mixes with other aerosols (Shin et al., 2015). 
Table 5. Parameters for cases 1 and 2 for group 6 at Osaka, linear particle depolarization ratio $\left(\delta_{\mathrm{P}}^{\mathrm{S}}\right)$ at $440,675,870$, and $1020 \mathrm{~nm}$ derived from the sun-sky radiometer data, absorption-related Ångström exponent $\left(\AA_{\mathrm{A}}\right)$, coarse-mode fraction on the basis of the volume concentration $\left(\mathrm{CMF}_{\mathrm{vc}}\right)$, and dust ratio $\left(R_{\mathrm{D}}\right)$ at $1020 \mathrm{~nm}$.

\begin{tabular}{|c|c|c|c|c|c|c|c|}
\hline & \multicolumn{4}{|c|}{$\delta_{\mathrm{P}}^{\mathrm{S}}$} & \multirow[t]{2}{*}{$\AA_{\mathrm{A}}$} & \multirow[t]{2}{*}{$\mathrm{CMF}_{\mathrm{vc}}$} & \multirow[t]{2}{*}{$R_{\mathrm{D}}$} \\
\hline & $440 \mathrm{~nm}$ & $675 \mathrm{~nm}$ & $870 \mathrm{~nm}$ & $1020 \mathrm{~nm}$ & & & \\
\hline Case 1 & $0.19 \pm 0.02$ & $0.24 \pm 0.01$ & $0.27 \pm 0.01$ & $0.29 \pm 0.01$ & $2.12 \pm 0.38$ & $0.87 \pm 0.01$ & $0.88 \pm 0.02$ \\
\hline Case 2 & $0.15 \pm 0.02$ & $0.24 \pm 0.01$ & $0.26 \pm 0.01$ & $0.27 \pm 0.01$ & $1.58 \pm 0.09$ & $0.92 \pm 0.01$ & $0.81 \pm 0.03$ \\
\hline
\end{tabular}
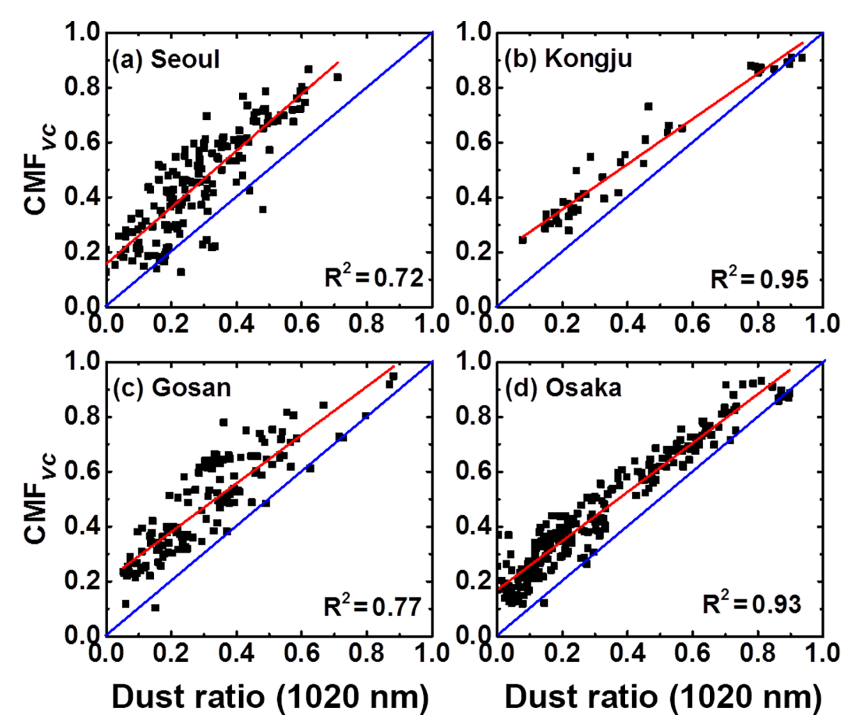

Figure 15. Correlation plots of the dust ratio at $1020 \mathrm{~nm}$ vs. the volume concentration in the coarse-mode fraction of the particle size distribution.

This increased possibility is corroborated by the results for the case of Osaka (see group 6). Table 5 shows for this case that $\delta_{\mathrm{P}}^{\mathrm{S}}, \mathrm{SSA}$, and the particle size distribution clearly depend on the altitude of the dust plume. $R_{\mathrm{D}}$ and $\mathrm{CMF}_{\mathrm{vc}}$ show very similar values with respect to case 1 . The average value of the difference between $R_{\mathrm{D}}$ and $\mathrm{CMF}_{\mathrm{vc}}$ is $0.004 \pm 0.008$ for the case that the main part of the dust plume is transported above the PBL (case 1). This difference between $R_{\mathrm{D}}$ and $\mathrm{CMF}_{\mathrm{vc}}$ increases to $0.11 \pm 0.04$ when the dust plume is transported near the surface, as can be seen from $\delta_{\mathrm{P}}^{\mathrm{LW}}$ of case 2 . From these results we can infer that the coarse mode is mostly composed of pure dust particles without that mixing with other types of particle occurred during transport above the PBL. However, the ratio of dust particles to non-dust coarse-mode particles decreases as the result of mixing processes during transport. These phenomena can be explained by the variation of the volume median radius ( $\mathrm{Rv}$ ).

The volume median radius of the coarse mode $\left(\mathrm{Rv}_{\mathrm{c}}\right)$ of 3.21-3.27 $\mu \mathrm{m}$ for urban-industrial aerosols generated by fossil fuel combustion and biomass burning aerosols produced by forest and grassland fires is higher than the $\mathrm{Rv}_{\mathrm{c}}$ of $2.62-$
$3.05 \mu \mathrm{m}$ of desert dust particles (Dubovik et al., 2002; Eck et al., 2010). In this study, $\mathrm{Rv}_{\mathrm{c}}$ shows low values when the observed particles are nearly pure dust. The average $\mathrm{Rv}_{\mathrm{c}}$ at Dunhuang is $1.88 \mu \mathrm{m}$ (except 8 April 2012). This value is quite similar to $2 \mu \mathrm{m}$ of $\mathrm{Rv}_{\mathrm{c}}$ for dust that originated from China and was measured over Japan (Tanaka et al., 1989). The average $\mathrm{Rv}_{\mathrm{c}}$ at Osaka decreases from 2.85 to $1.85 \mu \mathrm{m}$ between group 1 and group 6 , respectively. The other sites show the same pattern of decreasing values between groups 1 to 6 . The average $\mathrm{Rv}_{\mathrm{c}}$ of 2.15 at Kongju and $1.77 \mu \mathrm{m}$ at Gosan (group 6) also shows values that are similar to the values found in the dust source region. The average $R v_{c}$ of the other groups is higher than $\mathrm{Rv}_{\mathrm{c}}$ of dust in the source region. We find the highest values in group 1, i.e., 3.05, 2.72, 2.58, and $2.85 \mu \mathrm{m}$ at Seoul, Kongju, Gosan, and Osaka, respectively.

\section{Summary and conclusion}

In this study we investigated the reliability of the linear particle depolarization ratio $\left(\delta_{\mathrm{P}}^{\mathrm{S}}\right)$ that is derived by AERONET sun-sky radiometers. This parameter can be used for detecting dust particles. We compared data obtained from AERONET to the linear particle depolarization ratios measured by lidar $\left(\delta_{\mathrm{P}}^{\mathrm{L}}\right)$. We considered low (cases dominated by pollution particles) to high linear particle depolarization ratios (cases dominated by Asian dust) at four downwind regions (Seoul, Kongju, Gosan, and Osaka) of Asian dust. We calculated the column-integrated weighted $\delta_{\mathrm{P}}^{\mathrm{L}}\left(\delta_{\mathrm{P}}^{\mathrm{CL}}\right)$ and compared these values with $\delta_{\mathrm{P}}^{\mathrm{S}}$. The strongest correlation exists between $\delta_{\mathrm{P}}^{\mathrm{S}}$ at $1020 \mathrm{~nm}$ and $\delta_{\mathrm{P}}^{\mathrm{CL}}$. However, that latter value was measured at $532 \mathrm{~nm}$. Values are 0.90, 0.92, 0.79, and 0.89 for the sites at Seoul, Kongju, Gosan, and Osaka, respectively. The correlation decreased with decreasing wavelength that was used by the AERONET instrument. The correlation coefficient was $0.89,0.92,0.76$, and 0.88 at $870 \mathrm{~nm}$ at Seoul, Kongju, Gosan, and Osaka, respectively. The correlation at $675 \mathrm{~nm}$ is even weaker. We find values of $0.81,0.90$, 0.64 , and 0.81 at Seoul, Kongju, Gosan, and Osaka, respectively. The correlation coefficient at $440 \mathrm{~nm}$ is significantly lower. We find values of $0.38,0.62,0.26$, and 0.28 at Seoul, Kongju, Gosan, and Osaka, respectively. We assume that the low correlation is related to the size of fine-mode particles. 
However, more data are needed in order to better understand the reasons for the low correlation at $440 \mathrm{~nm}$.

Despite the discrepancy of the lidar ratios measured with lidar and inferred from AERONET sun photometer we are of the opinion that $\delta_{\mathrm{P}}^{\mathrm{S}}$ at $1020 \mathrm{~nm}$ can be used as a parameter to estimate the variation of optical and microphysical properties of dust when it is mixed with anthropogenic pollution particles. There is a clear pattern of variation of the fine and coarse modes of the volume particle size distributions in the context of changes of the value of $\delta_{\mathrm{P}}^{\mathrm{S}}$ at $1020 \mathrm{~nm}$. Fine-mode dominant volume particle size distributions are present for low values of $\delta_{\mathrm{P}}^{\mathrm{S}}$ at $1020 \mathrm{~nm}$. The fine-mode fraction of the volume particle size distribution decreases and the CMF of the particle size distribution increases when the $\delta_{\mathrm{P}}^{\mathrm{S}}$ at $1020 \mathrm{~nm}$ increases.

The SSA spectra show clearly distinguishable patterns when compared to the variation of $\delta_{\mathrm{P}}^{\mathrm{S}}$ at $1020 \mathrm{~nm}$. The SSA decreases with increasing measurement wavelength for low values of $\delta_{\mathrm{P}}^{\mathrm{S}}$ at $1020 \mathrm{~nm}$. In contrast, the SSA increases with increasing wavelength for high values of $\delta_{\mathrm{P}}^{\mathrm{S}}$ at $1020 \mathrm{~nm}$.

The dust ratio $\left(R_{\mathrm{D}}\right)$ can be derived from the $\delta_{\mathrm{P}}^{\mathrm{S}}$ at $1020 \mathrm{~nm}$. The $R_{\mathrm{D}}$ is approximately 0.12 to 0.17 lower than what we find from the CMF of the volume concentration $\left(\mathrm{CMF}_{\mathrm{vc}}\right)$. However, if $\delta_{\mathrm{P}}^{\mathrm{S}}$ at $1020 \mathrm{~nm}$ is larger than 0.25 , then $R_{\mathrm{D}}$ is similar to the value of $\mathrm{CMF}_{\mathrm{vc}}$, and the difference between these two parameters is less than 0.04 . We conclude that the values of $\delta_{\mathrm{P}}^{\mathrm{S}}$ at $1020 \mathrm{~nm}$ can be used to estimate the dust ratio. The dust ratio estimated in that way can then be used as basic information that could allow us to calculate the mass concentration of Asian dust and air pollutants in terms of columnintegrated values.

We conclude that on the basis of this first study values of $\delta_{\mathrm{P}}^{\mathrm{S}}$ at $1020 \mathrm{~nm}$ provide comparably reliable information with regard to identifying the presence of Asian dust particles in mixed aerosol plumes. The values of $\delta_{\mathrm{P}}^{\mathrm{S}}$ at $1020 \mathrm{~nm}$ are high for high dust concentrations and small for low dust concentrations. This means that $\delta_{\mathrm{P}}^{\mathrm{S}}$ at $1020 \mathrm{~nm}$ can be used to retrieve the dust ratio in mixed dust plumes.

Regardless of these findings we will carry out more studies in order to confirm these preliminary results. We also need to keep in mind that we cannot identify the vertical distribution of dust particles on the basis of $\delta_{\mathrm{P}}^{\mathrm{S}}$ because $\delta_{\mathrm{P}}^{\mathrm{S}}$ is a columnintegrated value.

Data availability. The AERONET sun-sky radiometer inversion data are available at https://aeronet.gsfc.nasa.gov/. The lidar data are available at http://www-lidar.nies.go.jp/.

Competing interests. The authors declare that they have no conflict of interest.
Acknowledgements. This work was funded by the Korea Meteorological Administration Research and Development Program under grant KMIPA 2015-6150. This work was supported by a National Research Foundation of Korea (NRF) grant funded by the South Korean government (MEST) (NRF-2015R1D1A1A09058269). This research was also supported by the International Environmental Research Center (IERC). Lidar data were provided by courtesy of AD-Net (http://www-lidar.nies.go.jp/AD-Net).

Edited by: M. Tesche

Reviewed by: three anonymous referees

\section{References}

Alfaro, S. C., Lafon, S., Rajot, J. L., Formenti, P., Gaudichet, A., and Maillé, M.: Iron oxides and light absorption by pure desert dust: An experimental study, J. Geophys. Res., 109, D08208, https://doi.org/10.1029/2003JD004374, 2004.

Ansmann, A., Tesche, M., Seifert P, Groß, S., Freudenthaler, V., Apituley, A., Wilson, K. M., Serikov, I., Linne, H., Heinold, B., Hiebsch, A., Schnell, F., Schmidt, J., Mattis, I., Wandinger, U., and Wiegner, M.: Ash and fine-mode particle mass profiles from EARLINET-AERONET observations over central Europe after the eruptions of the Eyjafjallajökull volcano in 2010, J. Geophys. Res., 116, D00U02, https://doi.org/10.1029/2010JD015567, 2011.

Bergstrom, R. W., Russell, P. B., and Hignett, P.: Wavelength dependence of the absorption of black carbon particles: Predictions and results from the TARFOX experiment and implications for the aerosol single scattering albedo, J. Atmos. Sci., 59, 567-577, 2002.

Bohren, C. F. and Huffman, D. R.: Absorption and Scattering by a Sphere, in Absorption and Scattering of Light by Small Particles, Wiley-VCH Verlag GmbH, 82-129, available at: http://onlinelibrary.wiley.com/doi/10.1002/9783527618156. ch4/summary (last access: 27 December 2016), 1983.

Bond, T. C. and Bergstrom, R. W.: Light Absorption by Carbonaceous Particles: An Investigative Review, Aerosol Sci. Tech., 40, 27-67, https://doi.org/10.1080/02786820500421521, 2006.

Bravo-Aranda, J. A., Titos, G., Granados-Munoz, M. J., GuerreroRascado, J. L., Navas-Guzman, F., Valenzuela, A., Lyamani, H., Olmo, F. J., Andrey, J., and Alados-Arboledas, L.: Study of mineral dust entrainment in the planetary boundary layer by lidar depolarisation technique, Tellus B, 67, 26180, https://doi.org/10.3402/tellusb.v67.26180, 2015.

Burton, S. P., Ferrare, R. A., Vaughan, M. A., Omar, A. H., Rogers, R. R., Hostetler, C. A., and Hair, J. W.: Aerosol classification from airborne HSRL and comparisons with the CALIPSO vertical feature mask, Atmos. Meas. Tech., 6, 13971412, https://doi.org/10.5194/amt-6-1397-2013, 2013.

Burton, S. P., Vaughan, M. A., Ferrare, R. A., and Hostetler, C. A.: Separating mixtures of aerosol types in airborne High Spectral Resolution Lidar data, Atmos. Meas. Tech., 7, 419-436, https://doi.org/10.5194/amt-7-419-2014, 2014.

Cairo, F., Donfrancesco, G. D., Adriani, A., Pulvirenti, L., and Fierli, F.: Comparison of various linear depolarization parameters measured by lidar, Appl. Opt., 38, 4425-4432, https://doi.org/10.1364/AO.38.004425, 1999. 
Chin, M., Diehl, T., Dubovik, O., Eck, T. F., Holben, B. N., Sinyuk, A., and Streets, D. G.: Light absorption by pollution, dust, and biomass burning aerosols: a global model study and evaluation with AERONET measurements, Ann. Geophys., 27, 3439-3464, https://doi.org/10.5194/angeo-27-3439-2009, 2009.

Derimian, Y., Karnieli, A., Kaufman, Y. J., Andreae, M. O., Andreae, T. W., Dubovik, O., Maenhaut, W., and Koren, I.: The role of iron and black carbon in aerosol light absorption, Atmos. Chem. Phys., 8, 3623-3637, https://doi.org/10.5194/acp-8-36232008, 2008.

Dubovik, O., Holben, B., Eck, T. F., Smirnov, A., Kaufman, Y. J., King, M. D., Tanré, D., and Slutsker, I.: Variability of Absorption and Optical Properties of Key Aerosol Types Observed in Worldwide Locations, J. Atmos. Sci., 59, 590-608, https://doi.org/10.1175/15200469(2002)059<0590:VOAAOP>2.0.CO;2, 2002.

Dubovik, O., Sinyuk, A., Lapyonok, T., Holben, B. N., Mishchenko, M., Yang, P., Eck, T. F., Volten, H., Muñoz, O., Veihelmann, B., van der Zande, W. J., Leon, J.-F., Sorokin, M., and Slutsker, I.: Application of spheroid models to account for aerosol particle nonsphericity in remote sensing of desert dust, J. Geophys. Res., 111, D11208, https://doi.org/10.1029/2005JD006619, 2006.

Eck, T. F., Holben, B. N., Reid, J. S., Dubovik, O., Smirnov, A., O'Neill, N. T., Slutsker, I., and Kinne, S.: Wavelength dependence of the optical depth of biomass burning, urban, and desert dust aerosols, J. Geophys. Res., 104, 31333-31349, https://doi.org/10.1029/1999JD900923, 1999.

Eck, T. F., Holben, B. N., Dubovik, O., Smirnov, A., Goloub, P., Chen, H. B., Chatenet, B., Gomes, L., Zhang, X.-Y., Tsay, S.C., Ji, Q., Giles, D., and Slutsker, I.: Columnar aerosol optical properties at AERONET sites in central eastern Asia and aerosol transport to the tropical mid-Pacific, J. Geophys. Res., 110, D06202, https://doi.org/10.1029/2004JD005274, 2005.

Eck, T. F., Holben, B. N., Sinyuk, A., Pinker, R. T., Goloub, P., Chen, H., Chatenet, B., Li, Z., Singh, R. P., Tripathi, S. N., Reid, J. S., Giles, D. M., Dubovik, O., O’Neill, N. T., Smirnov, A., Wang, P., and Xia, X.: Climatological aspects of the optical properties of fine/coarse mode aerosol mixtures, J. Geophys. Res., 115, D19205, https://doi.org/10.1029/2010JD014002, 2010.

Fernald, F. G.: Analysis of atmospheric lidar observations - Some comments, Appl. Optics, 23, 652-653, 1984.

Freudenthaler, V.: About the effects of polarising optics on lidar signals and the $\Delta 90$ calibration, Atmos. Meas. Tech., 9, 41814255, https://doi.org/10.5194/amt-9-4181-2016, 2016.

Freudenthaler, V., Esselborn, M., Wiegner, M., Heese, B., Tesche, M., Ansmann, A., Müller, D., Althausen, D., Wirth, M., Fix, A., Ehret, G., Knippertz, P., Toledano, C., Gasteiger, J., Garhammer, M., and Seefeldner, M.: Depolarization ratio profiling at several wavelengths in pure Saharan dust during SAMUM 2006, Tellus B, 61, 165-179, https://doi.org/10.1111/j.16000889.2008.00396.x, 2009.

Giles, D. M., Holben, B. N., Eck, T. F., Sinyuk, A., Smirnov, A., Slutsker, I., Dickerson, R. R., Thompson, A. M., and Schafer, J. S.: An analysis of AERONET aerosol absorption properties and classifications representative of aerosol source regions, J. Geophys. Res., 117, D17203, https://doi.org/10.1029/2012JD018127, 2012.

Gong, S. L., Zhang, X. Y., Zhao, T. L., McKendry, I. G., Jaffe, D. A., and Lu, N. M.: Characterization of soil dust aerosol in
China and its transport and distribution during 2001 ACE-Asia: 2. Model simulation and validation, J. Geophys. Res., 108, 4262, https://doi.org/10.1029/2002JD002633, 2003.

Haarig, M., Ansmann, A., Althausen, D., Klepel, A., Groß, S., Freudenthaler, V., Toledano, C., Mamouri, R.-E., Farrell, D. A., Prescod, D. A., Marinou, E., Burton, S. P., Gasteiger, J., Engelmann, R., and Baars, H.: Triple-wavelength depolarization-ratio profiling of Saharan dust over Barbados during SALTRACE in 2013 and 2014, Atmos. Chem. Phys. Discuss., https://doi.org/10.5194/acp-2017-170, in review, 2017.

Haywood, J. M., Allan, R. P., Culverwell, I., Slingo, T., Milton, S., Edwards, J., and Clerbaux, N.: Can desert dust explain the outgoing longwave radiation anomaly over the Sahara during July 2003?, J. Geophys. Res., 110, D05105, https://doi.org/10.1029/2004JD005232, 2005.

Holben, B. N., Eck, T. F., Slutsker, I., Tanré, D., Buis, J. P., Setzer, A., Vermote, E., Reagan, J. A., Kaufman, Y. J., Nakajima, T., Lavenu, F., Jankowiak, I., and Smirnov, A.: AERONET - A Federated Instrument Network and Data Archive for Aerosol Characterization, Remote Sens. Environ., 66, 1-16, https://doi.org/10.1016/S0034-4257(98)00031-5, 1998.

Husar, R. B., Tratt, D. M., Schichtel, B. A., Falke, S. R., Li, F., Jaffe, D., Gassó, S., Gill, T., Laulainen, N. S., Lu, F., Reheis, M. C., Chun, Y., Westphal, D., Holben, B. N., Gueymard, C., McKendry, I., Kuring, N., Feldman, G. C., McClain, C., Frouin, R. J., Merrill, J., DuBois, D., Vignola, F., Murayama, T., Nickovic, S., Wilson, W. E., Sassen, K., Sugimoto, N., and Malm, W. C.: Asian dust events of April 1998, J. Geophys. Res., 106, 18317-18330, https://doi.org/10.1029/2000JD900788, 2001.

IPCC: Climate Change 2013 - The Physical Science Basis: Working Group I Contribution to the Fifth Assessment Report of the Intergovernmental Panel on Climate Change, edited by: Stocker, T. F., Qin, D., Plattner, G.-K., Tignor, M., Allen, S. K., Boschung, J., Nauels, A., Xia, Y., Bex, V., and Midgley, P. M., Cambridge University Press Cambridge, UK, and New York, NY, USA, 2013.

Iwasaka, Y., Shibata, T., Nagatani, T., Shi, G.-Y., Kim, Y. S., Matsuki, A., Trochkine, D., Zhang, D., Yamada, M., Nagatani, M., Nakata, H., Shen, Z., Li, G., Chen, B., and Kawahira, K.: Large depolarization ratio of free tropospheric aerosols over the Taklamakan Desert revealed by lidar measurements: Possible diffusion and transport of dust particles, J. Geophys. Res., 108, 8652, https://doi.org/10.1029/2002JD003267, 2003.

Jickells, T. D., An, Z. S., Andersen, K. K., Baker, A. R., Bergametti, G., Brooks, N., Cao, J. J., Boyd, P. W., Duce, R. A., Hunter, K. A., Kawahata, H., Kubilay, N., laRoche, J., Liss, P. S., Mahowald, N., Prospero, J. M., Ridgwell, A. J., Tegen, I., and Torres, R.: Global Iron Connections Between Desert Dust, Ocean Biogeochemistry, and Climate, Science, 308, 6771, https://doi.org/10.1126/science.1105959, 2005.

Kanayama, S., Yabuki, S., Yanagisawa, F., and Motoyama, R.: The chemical and strontium isotope composition of atmospheric aerosols over Japan: the contribution of long-rangetransported Asian dust (Kosa), Atmos. Environ., 36, 5159-5175, https://doi.org/10.1016/S1352-2310(02)00587-3, 2002.

Kim, D., Chin, M., Yu, H., Eck, T. F., Sinyuk, A., Smirnov, A., and Holben, B. N.: Dust optical properties over North Africa and Arabian Peninsula derived from the AERONET dataset, Atmos. 
Chem. Phys., 11, 10733-10741, https://doi.org/10.5194/acp-1110733-2011, 2011.

Kinne, S., Schulz, M., Textor, C., Guibert, S., Balkanski, Y., Bauer, S. E., Berntsen, T., Berglen, T. F., Boucher, O., Chin, M., Collins, W., Dentener, F., Diehl, T., Easter, R., Feichter, J., Fillmore, D., Ghan, S., Ginoux, P., Gong, S., Grini, A., Hendricks, J., Herzog, M., Horowitz, L., Isaksen, I., Iversen, T., Kirkevåg, A., Kloster, S., Koch, D., Kristjansson, J. E., Krol, M., Lauer, A., Lamarque, J. F., Lesins, G., Liu, X., Lohmann, U., Montanaro, V., Myhre, G., Penner, J., Pitari, G., Reddy, S., Seland, O., Stier, P., Takemura, T., and Tie, X.: An AeroCom initial assessment - optical properties in aerosol component modules of global models, Atmos. Chem. Phys., 6, 1815-1834, https://doi.org/10.5194/acp-61815-2006, 2006.

Lafon, S., Rajot, J.-L., Alfaro, S. C., and Gaudichet, A.: Quantification of iron oxides in desert aerosol, Atmos. Environ., 38, 12111218, https://doi.org/10.1016/j.atmosenv.2003.11.006, 2004.

Lafon, S., Sokolik, I. N., Rajot, J. L., Caquineau, S., and Gaudichet, A.: Characterization of iron oxides in mineral dust aerosols: Implications for light absorption, J. Geophys. Res., 111, D21207, https://doi.org/10.1029/2005JD007016, 2006.

Lee, J., Kim, J., Song, C. H., Ryu, J.-H., Ahn, Y.-H., and Song, C. K.: Algorithm for retrieval of aerosol optical properties over the ocean from the Geostationary Ocean Color Imager, Remote Sens. Environ., 114, 1077-1088, https://doi.org/10.1016/j.rse.2009.12.021, 2010a.

Lee, K.-H., Muller, D., Noh, Y.-M., Shin, S.-K., and Shin, D.-H.: Depolarization Ratio Retrievals Using AERONET Sun Photometer Data, J. Opt. Soc. Korea, 14, 178-184, 2010 b.

Mamouri, R.-E. and Ansmann, A.: Potential of polarization/Raman lidar to separate fine dust, coarse dust, maritime, and anthropogenic aerosol profiles, Atmos. Meas. Tech. Discuss., https://doi.org/10.5194/amt-2017-131, in review, 2017.

Maring, H., Savoie, D. L., Izaguirre, M. A., Custals, L., and Reid, J. S.: Mineral dust aerosol size distribution change during atmospheric transport, J. Geophys. Res., 108, 8592, https://doi.org/10.1029/2002JD002536, 2003.

Müller, D., Ansmann, A., Freudenthaler, V., Kandler, K., Toledano, C., Hiebsch, A., Gasteiger, J., Esselborn, M., Tesche, M., Heese, B., Althausen, D., Weinzierl, B., Petzold, A., and von Hoyningen-Huene, W.: Mineral dust observed with AERONET Sun photometer, Raman lidar, and in situ instruments during SAMUM 2006: Shapedependent particle properties, J. Geophys. Res., 115, D11207, https://doi.org/10.1029/2009JD012523, 2010.

Müller, D., Lee, K.-H., Gasteiger, J., Tesche, M., Weinzierl, B., Kandler, K., Müller, T., Toledano, C., Otto, S., Althausen, D., and Ansmann, A.: Comparison of optical and microphysical properties of pure Saharan mineral dust observed with AERONET Sun photometer, Raman lidar, and in situ instruments during SAMUM 2006, J. Geophys. Res., 117, D07211, https://doi.org/10.1029/2011JD016825, 2012.

Müller, T., Schladitz, A., Kandler, K., and Wiedensohler, A.: Spectral particle absorption coefficients, single scattering albedos and imaginary parts of refractive indices from ground based in situ measurements at Cape Verde Island during SAMUM-2, Tellus B, 63, 573-588, https://doi.org/10.3402/tellusb.v63i4.16348, 2011.

Navas-Guzmán, F., Bravo-Aranda, J. A., Guerrero-Rascado, J. L., Granados-Muñuoz, M. J., PeDrez-Ramírez, D., Olmo, F. J., and
Alados-Arboledas, L.: Eruption of the Eyjafjallajöykull Volcano in spring 2010: Multiwavelength Raman lidar measurements of sulphate particles in the lower troposphere, J. Geophys. Res.Atmos., 118, 1804-1813, https://doi.org/10.1002/jgrd.50116, 2013.

Nishizawa, T., Sugimoto, N., Matsui, I., Shimizu, A., Hara, Y., Itsushi, U., Yasunaga, K., Kudo, R., and Kim, S. W.: Groundbased network observation using Mie-Raman lidars and multiwavelength Raman lidars and algorithm to retrieve distributions of aerosol components, J. Quant. Spectrosc. Ra., 188, 79-93, 2017.

Noh, Y. M.: Single-scattering albedo profiling of mixed Asian dust plumes with multiwavelength Raman lidar, Atmos. Environ., 95, 305-317, https://doi.org/10.1016/j.atmosenv.2014.06.028, 2014.

Noh, Y. M., Kim, Y. J., Choi, B. C., and Murayama, T.: Aerosol lidar ratio characteristics measured by a multi-wavelength Raman lidar system at Anmyeon Island, Korea, Atmos. Res., 86, 76-87, https://doi.org/10.1016/j.atmosres.2007.03.006, 2007.

Noh, Y. M., Kim, Y. J., and Müller, D.: Seasonal characteristics of lidar ratios measured with a Raman lidar at Gwangju, Korea in spring and autumn, Atmos. Environ., 42, 2208-2224, https://doi.org/10.1016/j.atmosenv.2007.11.045, 2008.

Noh, Y. M., Müller, D., Lee, H., Lee, K., and Kim, Y. J.: Columnar aerosol optical and radiative properties according to season and air mass transport pattern over East Asia, Environ. Monit. Assess., 184, 4763-4775, https://doi.org/10.1007/s10661-0112300-7, 2012a.

Noh, Y. M., Müller, D., Lee, H., Lee, K., Kim, K., Shin, S., and Kim, Y. J.: Estimation of radiative forcing by the dust and nondust content in mixed East Asian pollution plumes on the basis of depolarization ratios measured with lidar, Atmos. Environ., 61, 221-231, https://doi.org/10.1016/j.atmosenv.2012.07.034, 2012b.

Noh, Y. M., Müller, D., Lee, H., and Choi, T. J.: Influence of biogenic pollen on optical properties of atmospheric aerosols observed by lidar over Gwangju, South Korea, Atmos. Environ., 69, 139-147, https://doi.org/10.1016/j.atmosenv.2012.12.018, 2013a.

Noh, Y. M., Lee, H., Mueller, D., Lee, K., Shin, D., Shin, S., Choi, T. J., Choi, Y. J., and Kim, K. R.: Investigation of the diurnal pattern of the vertical distribution of pollen in the lower troposphere using LIDAR, Atmos. Chem. Phys., 13, 7619-7629, https://doi.org/10.5194/acp-13-7619-2013, 2013b.

Noh, Y. M., Shin, S.-K., Lee, K., Müller, D., and Kim, K.: Utilization of the depolarization ratio derived by AERONET sun/sky radiometer data for type confirmation of a mixed aerosol plume over East Asia, Int. J. Remote Sens., 37, 2180-2197, https://doi.org/10.1080/01431161.2016.1176274, 2016a.

Noh, Y. M., Lee, K., Kim, K., Shin, S.-K., Müller, D., and Shin, D. H.: Influence of the vertical absorption profile of mixed Asian dust plumes on aerosol direct radiative forcing over East Asia, Atmos. Environ., 138, 191-204, https://doi.org/10.1016/j.atmosenv.2016.04.044, 2016 b.

Russell, P. B., Bergstrom, R. W., Shinozuka, Y., Clarke, A. D., DeCarlo, P. F., Jimenez, J. L., Livingston, J. M., Redemann, J., Dubovik, O., and Strawa, A.: Absorption Angstrom Exponent in AERONET and related data as an indicator of aerosol composition, Atmos. Chem. Phys., 10, 1155-1169, https://doi.org/10.5194/acp-10-1155-2010, 2010. 
Sakai, T., Nagai, T., Nakazato, M., Mano, Y., and Matsumura, T.: Ice clouds and Asian dust studied with lidar measurements of particle extinction-to-backscatter ratio, particle depolarization, and water-vapor mixing ratio over Tsukuba, Appl. Optics, 42, 7103-7116, 2003.

Sassen, K., Wang, Z., and Liu, D.: Global distribution of cirrus clouds from CloudSat/Cloud-Aerosol Lidar and Infrared Pathfinder Satellite Observations (CALIPSO) measurements, J. Geophys. Res., 113, D00A12, https://doi.org/10.1029/2008JD009972, 2008.

Shimizu, A., Sugimoto, N., Matsui, I., Arao, K., Uno, I., Murayama, T., Kagawa, N., Aoki, K., Uchiyama, A., and Yamazaki, A.: Continuous observations of Asian ust and other aerosols by polarization lidars in China and Japan during ACE-Asia, J. Geophys. Res., 109, D19S17, https://doi.org/10.1029/2002JD003253, 2004.

Shimizu, A., Nishizawa, T., Jin, Y., Kim, S. W., Wang, Z., Batdorj, D., and Sugimoto, N.: Evolution of a lidar network for tropospheric aerosol detection in East Asia, Opt. Eng., 56, 031219, https://doi.org/10.1117/1.OE.56.3.031219, 2016.

Shin, S.-K., Müller, D., Lee, C., Lee, K. H., Shin, D., Kim, Y. J., and Noh, Y. M.: Vertical variation of optical properties of mixed Asian dust/pollution plumes according to pathway of air mass transport over East Asia, Atmos. Chem. Phys., 15, 6707-6720, https://doi.org/10.5194/acp-15-6707-2015, 2015.

Sokolik, I. N. and Toon, O. B.: Incorporation of mineralogical composition into models of the radiative properties of mineral aerosol from UV to IR wavelengths, J. Geophys. Res., 104, 9423-9444, https://doi.org/10.1029/1998JD200048, 1999.

Sugimoto, N., Nishizawa, T., Shimizu, A., Matsui, I., and Jin, Y.: Characterization of aerosols in East Asia with the Asian Dust and Aerosol Lidar Observation Network (AD-Net), Lidar Remote Sensing for Environmental Monitoring XIV, Proc. SPIE, 9262, 92620K, https://doi.org/10.1117/12.2069892, 2014.

Sun, Y., Zhuang, G., Wang, Y., Zhao, X., Li, J., Wang, Z., and An, Z.: Chemical composition of dust storms in Beijing and implications for the mixing of mineral aerosol with pollution aerosol on the pathway, J. Geophys. Res., 110, D24209, https://doi.org/10.1029/2005JD006054, 2005.
Sun, Y., Zhuang, G., Huang, K., Li, J., Wang, Q., Wang, Y., Lin, Y., Fu, J. S., Zhang, W., Tang, A., and Zhao, X.: Asian dust over northern China and its impact on the downstream aerosol chemistry in 2004, J. Geophys. Res., 115, D00K09, https://doi.org/10.1029/2009JD012757, 2010.

Tanaka, M., Nakajima, T., Shiobara, M., Yamano, M., and Arao, K.: Aerosol optical characteristics in the yellow sand events observed in May, 1982 at Nagasaki - Part 1. Observations, J. Meteorol. Soc. Jpn., 67, 267-278, 1989.

Tesche, M., Ansmann, A., Müller, D., Althausen, D., Engelmann, R., Freudenthaler, V., and Groß, S.: Vertically resolved separation of dust and smoke over Cape Verde using multiwavelength Raman and polarization lidars during Saharan Mineral Dust Experiment 2008, J. Geophys. Res., 114, D13202, https://doi.org/10.1029/2009JD011862, 2009.

Tesche, M., Müller, D., Gross, S., Ansmann, A., Althausen, D., Freudenthaler, V., Weinzierl, B., Veira, A., and Petzold, A.: Optical and microphysical properties of smoke over Cape Verde inferred from multiwavelength lidar measurements, Tellus B, 63, 677-694, https://doi.org/10.1111/j.1600-0889.2011.00549.x, 2011.

Volten, H., Muñoz, O., Rol, E., de Haan, J. F., Vassen, W., Hovenier, J. W., Muinonen, K., and Nousiainen, T.: Scattering matrices of mineral aerosol particles at $441.6 \mathrm{~nm}$ and $632.8 \mathrm{~nm}, \quad$ J. Geophys. Res., 106, 17375-17401, https://doi.org/10.1029/2001JD900068, 2001.

Whiteman, D. N., Melfi, S. H., and Ferrare, R. A.: Raman lidar system for the measurement of water vapor and aerosols in the Earth's atmosphere, Appl. Optics, 31, 3068-3082, 1992.

Yu, X., Cheng, T., Chen, J., and Liu, Y.: A comparison of dust properties between China continent and Korea, Japan in East Asia, Atmos. Environ., 40, 5787-5797, https://doi.org/10.1016/j.atmosenv.2006.05.013, 2006. 